\title{
USGS/NOAA Workshop on Mycobacteriosis in Striped Bass, May 7-10, 2006, Annapolis, Maryland
}

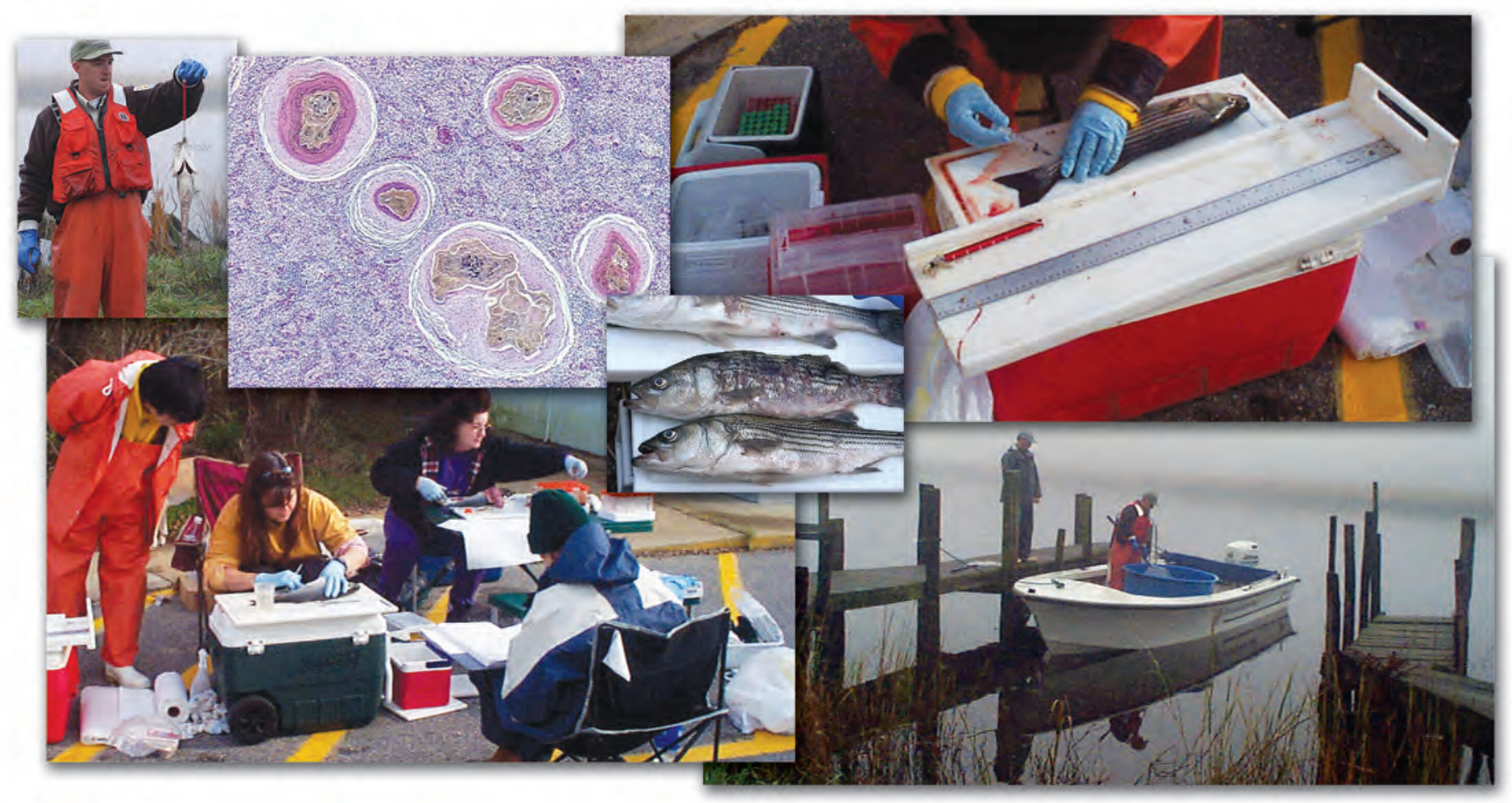

USGS Scientific Investigations Report 2006-5214 NOAA Technical Memorandum NOS NCCOS 41

U.S. Department of the Interior U.S. Geological Survey
U.S. Department of Commerce National Oceanic and Atmospheric Administration National Ocean Service 


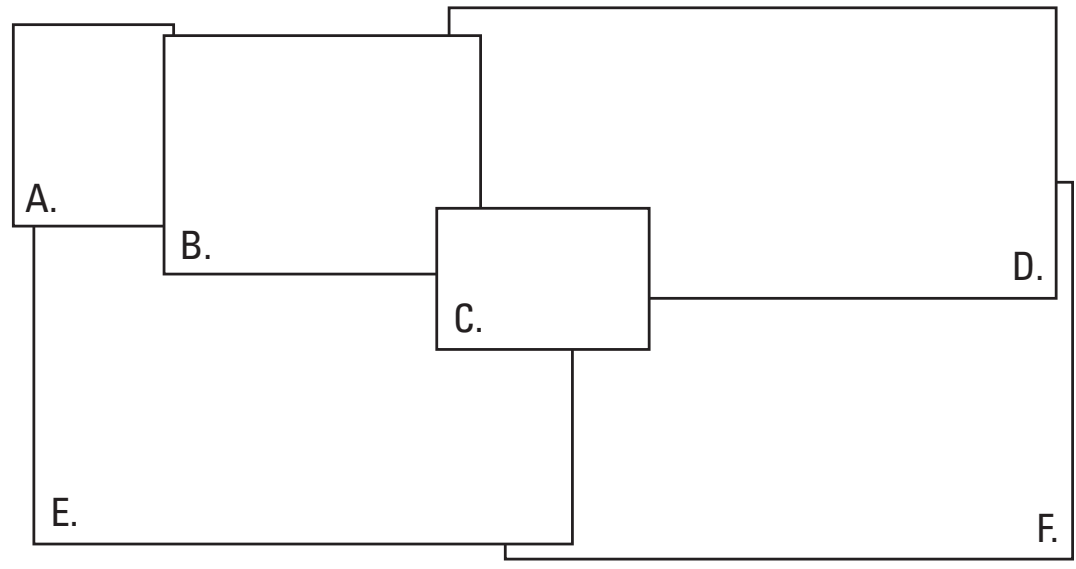

A. U.S. Fish and Wildlife Service biologist weighing Chesapeake Bay striped bass exhibiting skin lesions. Photo by Christine L. Densmore, U.S. Geological Survey

B. Stained tissue section taken from the spleen of a Chesapeake Bay striped bass exhibiting granulomatous lesions associated with a mycobacterial infection. Photo by David Gauthier, Virginia Institute of Marine Science

C. Chesapeake Bay striped bass exhibiting emaciation and skin lesions consistent with mycobacteriosis. Photo by Mark Matsche, Maryland Department of Natural Resources

D. Collection of blood sample from striped bass harvested from the Nanticoke River, Maryland, in November 2002. Photo by Mark Matsche, Maryland Department of Natural Resources

E. U.S. Geological Survey field crew processing striped bass as part of a mycobacteriosis survey conducted in the tidal portions of Chesapeake Bay rivers during 2002 and 2003. Photo by Mark Matsche, Maryland Department of Natural Resources

F. Live well transport and landing of striped bass by U.S. Fish and Wildlife personnel. Photo by Mark Matsche, Maryland Department of Natural Resources 


\section{USGS/NOAA Workshop on Mycobacteriosis in Striped Bass, May 7-10, 2006, Annapolis, Maryland}

Edited By Christopher A. Ottinger and John M. Jacobs

USGS Scientific Investigations Report 2006-5214

NOAA Technical Memorandum NOS NCCOS 41

U.S. Department of the Interior

U.S. Geological Survey
U.S.Department of Commerce

National Oceanic and Atmospheric Administration

National Ocean Service 


\title{
U.S. Department of the Interior DIRK KEMPTHORNE, Secretary
}

\author{
U.S. Geological Survey \\ Mark D. Myers, Director
}

\section{U.S. Deptartment of Commerce \\ CARLOS M. GUTIERREZ, Secretary}

\section{National Oceanic and Atmospheric Administration \\ Conrad C. Lautenbacher, Jr., Administrator \\ National Ocean Service \\ John (Jack) H. Dunnigan, Assistant Administrator}

U.S. Geological Survey, Reston, Virginia: 2006

For product and ordering information:

World Wide Web: http://www.usgs.gov/pubprod

Telephone: 1-888-ASK-USGS

For more information on the USGS--the Federal source for science about the Earth, its natural and living resources, natural hazards, and the environment:

World Wide Web: http://www.usgs.gov

Telephone: 1-888-ASK-USGS

This report has been reviewed by the U.S. Geological Survey and the National Ocean Service of the National Oceanic and Atmospheric Administration (NOAA) and approved for publication. Any use of trade, product, or firm names is for descriptive purposes only and does not imply endorsement by the U.S. Government.

Although this report is in the public domain, permission must be secured from the individual copyright owners to reproduce any copyrighted materials contained within this report.

Suggested citation:

Ottinger, C.A., and Jacobs, J.M., 2006, USGS/NOAA Workshop on Mycobacteriosis in Striped Bass, May 7-10, 2006, Annapolis, Maryland: U.S. Geological Survey Scientific Investigations Report 2006-5214 / National Oceanic and Atmospheric Administration Technical Memorandum NOS NCCOS 41, 42 p. 


\section{Contents}

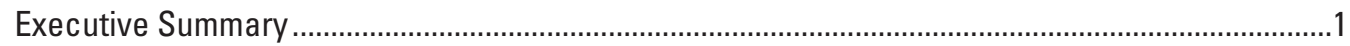

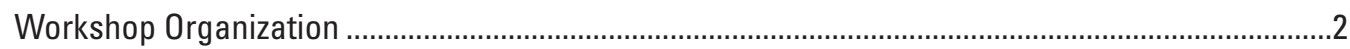

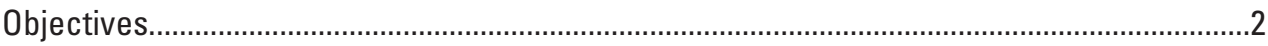

Technical Review Panel............................................................................................................

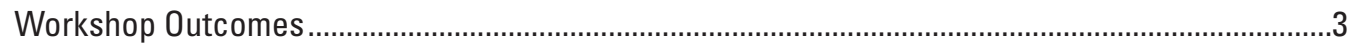

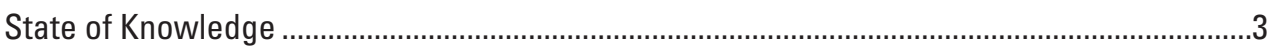

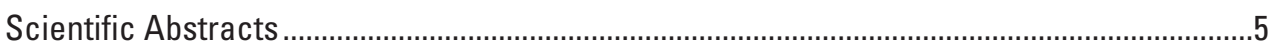

A historical perspective on diseases of striped bass with emphasis on

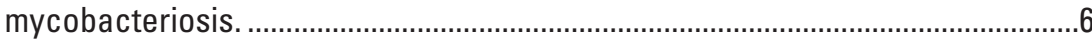

The ecology of mycobacteria infecting striped bass (Morone saxatilis) in Chesapeake Bay: A research plan.........................................................................

Striped bass mycobacteriosis: A zoonotic disease of concern in Chesapeake Bay. ......9

Striped bass disease overview for the past ten years plus...........................................10

Survey of gametes and juvenile striped bass (Morone saxatilis) for mycobacteriosis from the Chesapeake Bay: Sampling methods, external lesions, and histopathology. ...............................................................12

Microbiology of gametes and age 0-3 striped bass (Morone saxatilis)........................13

Mycobacterial infections in striped bass (Morone saxatilis) from upper and lower Chesapeake Bay: 2002 and 2003 pound net studies..................................15

Epizootiology of mycobacteriosis in Chesapeake Bay striped bass (Morone saxatilis): Large-scale field survey. ...................................................16

Mycobacteriosis in juvenile Atlantic menhaden.........................................................17

The influence of dietary intake on the progression and severity of mycobacteriosis in striped bass (Morone saxatilis). ...........................................19

Mycobacteriosis in Chesapeake Bay fishes: Perspectives and questions. ....................20

Initial investigation of the overall health and presence of mycobacteriosis in Roanoke River, NC, striped bass (Morone saxatilis)......................................22

Mycobacterial infections in striped bass (Morone saxatilis) from Delaware Bay.........23

Tag-recapture data from Chesapeake Bay striped bass indicate that

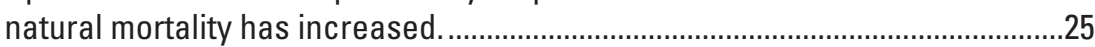

Epizootic mycobacteriosis in Chesapeake Bay striped bass: What is the fate

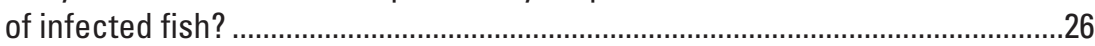

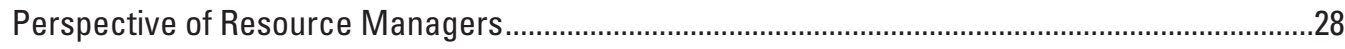

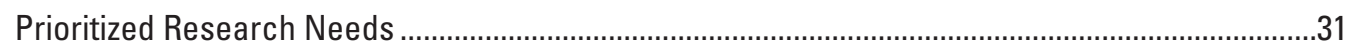

Research Integration and Role of Federal Agencies................................................................33

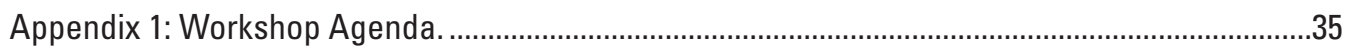

Appendix 2: Prioritized Research Agenda with Estimated Timelines for Completion......................37

Appendix 3: Participant List..................................................................................................... 


\title{
USGS/NOAA Workshop on Mycobacteriosis in Striped Bass, May 7 - 10, 2006, Annapolis, Maryland
}

\author{
By C. A. Ottinger and J.M. Jacobs
}

\section{Executive Summary}

As a Federal trust species, the well-being of the striped bass (Morone saxatilis) population along the Eastern Seaboard is of major concern to resource users. Striped bass are an extremely valuable commercial and recreational resource. As a principal piscivore in Chesapeake Bay, striped bass directly or indirectly interact with multiple trophic levels within the ecosystem and are therefore very sensitive to biotic and abiotic ecosystem changes. For reasons that have yet to be defined, the species has a high intrinsic susceptibility to mycobacteriosis. This disease has been impacting Chesapeake Bay striped bass since at least the 1980s as indicated by archived tissue samples. However, it was not until heightened incidences of fish with skin lesions in the Pocomoke River and other tributaries of the Chesapeake Bay were reported in the summer and fall of 1996 and 1997 that a great deal of public and scientific interest was stimulated about concerns for fish disease in the Bay.

By 2005, multiple research groups had studied or were independently investigating this disease issue. Identified research redundancies made apparent the need for improved communications, integration of science efforts, and resource optimization. In May of 2006, the U.S. Geological Survey (USGS), Leetown Science Center, partnered with the National Oceanographic and Atmospheric Administration/ National Ocean Service (NOAA/NOS), Cooperative Oxford Laboratory, to sponsor a workshop on mycobacteriosis in Chesapeake Bay striped bass. This workshop involved the principal Federal, State, and academic scientists involved with this issue as well as the resource managers. The goals of this workshop were to:

1. Establish the state of knowledge;

2. Develop a prioritized research agenda; and

3. Identify mechanisms by which research efforts could be optimized.

The workshop structure included oral presentations with associated extended abstracts, formal group discussions, and a panel discussion that involved resource managers from NOAA's National Marine Fisheries Service, the Maryland Department of Natural Resources, and the Virginia Marine Resources Commission. The workshop also included a review panel charged with assessing information generated in the workshop and providing input on state of knowledge, knowledge gaps, and information needs pertaining to mycobacteriosis in Chesapeake Bay striped bass. The review panel was composed of scientists from USGS, NOAA, Food and Drug Administration (FDA), U.S. Fish and Wildlife Sevice (USFWS), and Cornell University. Additional information and guidance was provided by the former head of the Tuberculosis/Mycobacteria group at the Centers for Disease Control and Prevention (CDC), Atlanta. The initial release of outcomes was made by way of a press conference held at the end of the workshop. The press conference featured a brief formal presentation followed by formal and informal question and answer sessions. Press conference attendees included reporters from the major regional newspapers (Baltimore Sun, Washington Post, etc.), the Associated Press, and a local television station.

A substantial portion of the research presented at the workshop resulted from projects that had been completed within the last year or from projects that were in progress. These new data created some additional challenges for the review panel. However, the willingness of workshop participants to provide the data made an up-to-date state of knowledge statement possible. Synthesis of multiple data sets that occurred as part of the workshop process made apparent trends that had been either partially recognized or not seen at all.

Mycobacteria-associated infection and disease in Chesapeake Bay striped bass is age and sex dependent. The relative prevalence and severity of the disease has both spatial and temporal components. Temporal components appear to be relatively stable, with the most severe disease occurring during the late summer and fall. Spatial components appear less stable, with the exception of potential foci located in the northern region of the Bay. Modes of disease transmission remain poorly described. Limited data indicate that infections can be transmitted via the water column. Additional data indicate the 
occurrence of mycobacteria associated with gametes, suggesting the possibility of adults transferring the infection to their progeny, a process known as vertical transmission. Multiple species of teleosts within Chesapeake Bay have been found to be infected with mycobacteria, suggesting the possibility of trophic transfers of infection.

Trophic interactions may also be affecting striped bass nutrition. Concurrent with an increase in skin lesions in the late 1990s was an elevated frequency of emaciated striped bass. Inadequate nutrition has been shown to increase severity and progression of mycobacteriosis in striped bass. However, mycobacteriosis is commonly associated with reductions in fitness. The question of whether Chesapeake Bay striped bass are skinny because of mycobacteriosis or whether poorly nourished and therefore skinny bass are developing the disease has yet to be answered. Data collected to date suggest that a combination of both scenarios may be occurring. Although there was some disagreement regarding modeling methods employed by the Atlantic States Marine Fisheries Commission (ASMFC) for stock assessment, population data generated through tagging programs in Chesapeake Bay seem to indicate that the natural mortality rate in the spawning component of the striped bass stock had increased dramatically ( $2 \mathrm{x}$ to $3 \mathrm{x}$ ) beginning in the late 1990s. The most recent tag return data indicate that natural mortality rates in the southern region of the Bay have returned to historic norms. The rate in the northern region of the Bay remains high. The relationship, if any, between this apparent increase in natural mortality and the mycobacteriosis epizootic has yet to be established. However, the simultaneous occurrence of the two events has raised concerns about the potential impact of mycobacteriosis on the striped bass population. Corresponding declines in spawning stock biomass and recruitment have not been noted.

Determining the impact of mycobacteriosis on striped bass populations throughout the Chesapeake Bay watershed was the top priority of both resource managers and participating scientists. Other priorities included developing a better understanding of mycobacterial ecology, especially as it relates to disease transmission, and the characterization of stressors that increase striped bass disease susceptibility. The development of the prioritized research agenda was supplemented by the identification of several overarching themes. Workshop participants recognized that the scope of this disease issue transcends individual research or resource management organizations and that its resolution will require integration of effort and optimization of available resources. The need to consider socioeconomic and human health concerns was also recognized. Final recommendations from the workshop included the development of a multiagency steering committee that will be charged with issues including:

1. The continued development of diagnostic tools and methods standardization;

2. Development of a standardized data base for all data related to mycobacteriosis/striped bass research in Chesapeake Bay as well as adjacent estuaries;
3. Transfer of data for use in ecosystem modeling such as the program currently being developed by the NOAA Chesapeake Bay Program; and

4. The development of a communications network designed to rapidly disseminate research findings, announce upcoming research activities, and provide guidance on research needs as the knowledge base evolves.

While mycobacteriosis in Chesapeake Bay striped bass was once viewed as a single resource issue, the complexity that is only beginning to be appreciated is forcing a broader view in the context of ecosystem health and ecosystem change. Striped bass populations have historically been managed in isolation. New fishery management models include multiple stocks in recognition of the ecological relatedness of individual species. Fishery managers once viewed disease as an unexplainable component of natural mortality in population models. This perspective is slowly changing. Now, integrated fisheries management requires the consideration of interactions (biotic and abiotic) and thus dramatically increases information needs and, by extension, provides data about the ecosystem that has broader application. This information need can best be met through highly integrated and well-coordinated research programs. The development of such a program will be the ultimate indicator of the success of the USGS/ NOAA Workshop on Mycobacteriosis in Striped Bass.

\section{Workshop Organization}

\section{Objectives}

The overarching goal of this workshop was to provide a synthesis of current understanding regarding mycobacteriosis and its ecological effects, and to provide recommendations that will facilitate a coordinated approach by funding agencies and researchers in their collective efforts to effectively and efficiently address this research topic.

Specific objectives of this workshop were to:

1. Characterize the state of knowledge regarding mycobacteriosis in Chesapeake Bay striped bass;

2. Assess striped bass - mycobacteriosis relationships throughout Chesapeake Bay and place them into a geographic perspective relative to the conditions in other East Coast coastal systems;

3. Identify and describe ongoing research projects relevant to the disease;

4. Provide a consensus-derived prioritized research approach for the short term (1-2 years) and long term (3-5 years) that will yield a better understanding and improved 
management advice pertaining to mycobacteriosis issues pertinent to Chesapeake Bay ecosystem-based management and restoration;

5. Identify strategies for the implementation of research plans; and

6. Produce a workshop technical report and non-technical informational products for use by the larger research and resource management communities, lawmakers, and the general public.

\section{Technical Review Panel}

Based on the submitted research summaries, presentations, and existing peer-reviewed literature, the review panel was charged with making determinations on the state of knowledge in areas related to pathogenesis, transmission, distribution, pathogen characterization, pathogen-host interactions, disease ecology, and host population effects. The panel was also asked to make recommendations on research prioritization using input from workshop breakout sessions. The review panel was composed of the following scientists with knowledge of and familiarity with the issue and the Bay (Table 1).

Table 1. Mycobacteriosis in Striped Bass Technical Review Panel

\begin{tabular}{ll}
\hline \multicolumn{1}{c}{ Name } & \multicolumn{1}{c}{ Affiliation } \\
\hline $\begin{array}{l}\text { Dr. Vicki Blazer } \\
\text { (Panel Chair) }\end{array}$ & US Geological Survey \\
& Leetown Science Center \\
& Kearneysville, WV \\
Dr. Kay Briggs & US Geological Survey \\
& Biological Resources \\
& Discipline \\
& Reston, VA \\
& US Fish and Wildlife Service \\
& Northeast Fisheries Center \\
Mr. John Coll & Lamar, PA \\
& NOAA/National Ocean Service \\
& Ecosystem Processes Division \\
Dr. Andrew Draxler & Highlands, NJ \\
& Cornell University \\
Dr. Rod Getchell & Veterinary Medical Center \\
& Ithaca, NY \\
Dr. Renate Reimschuessel & Food and Drug Administration \\
& Center of Veterinary Medicine \\
& Laurel, MD \\
(retired) & NOAA/National Ocean Service \\
& Oxford Marine Laboratory \\
& Oxford, MD \\
\hline
\end{tabular}

\section{Workshop Outcomes}

\author{
State of Knowledge
}

\author{
Presented by Vicki Blazer, Research Fishery Biologist \\ U.S. Geological Survey, Leetown Science Center \\ (representing the findings of the Technical Review \\ Panel)
}

Mycobacteriosis in Chesapeake Bay striped bass (Morone saxatilis) is characterized by cutaneous lesions, viscerallesions, or a combination of the two. These lesions are typified by a granulomatous inflammatory response to the mycobacteria that act as an intracellular pathogen in macrophages. Spleen and kidney are the primary target organs in Chesapeake Bay striped bass, but the disease can be systemic. Mycobacteriosis is a chronic disease that develops slowly. Pathogenesis is dependent on the Mycobacterium sp. involved, may be dose dependent, and is temperature dependent. Striped bass can be infected with mycobacteria without exhibiting pathology.

Mycobacteriosis has been impacting Chesapeake Bay striped bass since at least 1984 . The prevalence of this disease has increased in the Maryland portion of the Bay since 1998 as indicated by data from the Maryland Department of Natural Resources. Prevalence in the main stem of the Bay may have stabilized from 2003 to 2005 . The characterization of mycobacterial infection prevalence is complex and is based on age, sex, and life history. The development of disease is age dependent. Infections are observed in young-of-the-year striped bass. Granulomas containing acid-fast bacilli are observed in age 1 fish or older. Disease prevalence increases in both male and female fish to age 6 . After age 6, prevalence appears to decline in females. Male and female Chesapeake Bay striped bass exhibit different life histories, with the female fish leaving the Bay at a younger age. Infection prevalence of over $50 \%$ has been reported in 3 to 4 year male striped bass collected from commercial pound nets located at the mouths of rivers in both Virginia and Maryland. Infection and disease prevalence of approximately $80 \%$ have been reported for age 6 male and female fish.

Striped bass with mycobacteriosis have been harvested from the tidal portions of multiple rivers flowing into Chesapeake Bay and from the Bay's main stem. Main-stem samples containing diseased fish have come from both the Maryland and Virginia portions of the Bay. Rivers from which diseased striped bass have been obtained include the James, Rappahannock, and York in Virginia; the Virginia and Maryland portions of the Potomac; and the Chester, Choptank, Nanticoke, Pocomoke, and Sassafras in Maryland. Differences in infection and disease prevalence as well as disease severity have been observed between sample sites, but site-specific trends 
have yet to be established. Some temporal fluctuations in disease have been observed. Most notable is the increase in the frequency of skin lesions in the fall (September - November) relative to spring (March - May) and summer (June - August). Limited data have been obtained on mycobacteriosis in East Coast striped bass outside Chesapeake Bay. In Delaware Bay, a spleen-dominated disease presentation was observed but prevalence was low $(18 \%)$. The few mycobacterial isolates obtained were not those commonly obtained from Chesapeake Bay striped bass. Striped bass from Roanoke River (North Carolina) exhibited a spleen-dominated presentation and low prevalence (18\%). Infection was not confirmed by bacterial culture. Mycobacteriosis has been detected in the Atlantic Coast migratory stock and Chesapeake Bay spawning stock by histopathology; however, low sample size prohibited estimation of prevalence.

Multiple species of Mycobacterium have been isolated from Chesapeake Bay striped bass and some infections involve more than one Mycobacterium sp. Two new species, M. shottsii and M. pseudoshottsii, obtained from Chesapeake Bay striped bass have been described and officially recognized. The mycobacteria from the striped bass have different growth characteristics in vitro and little is known regarding virulence. Fatty acid differences in the cell walls of many of the Mycobacterium spp. infecting Chesapeake Bay striped bass have been documented and appear to be useful for speciation.

Little is known regarding the transmission of mycobacterial infections in Chesapeake Bay striped bass. Mycobacteria have been cultured from gamete samples obtained from spawning striped bass harvested from two rivers in Maryland. As was noted above, young-of-the-year striped bass are infected. The association of mycobacteria with gametes and young-of-the-year infection indicates the possibility of vertical transmission. However, there is no evidence to date to demonstrate if young-of-the-year fish are infected during development or sometime post hatch. Evidence for oral/food transmission has been developed for other teleost species. Striped bass prey species, such as Atlantic menhaden, can be infected. Limited laboratory data provide some evidence for possible aqueous horizontal exposure. Trauma injury resulting from nets, parasites, and catch and release angling or the culling of sublegal-length fish from commercial nets cannot be dismissed as a possible avenue for infection.

Some data are available on pathogen-host interactions. In vitro as well as in vivo studies have been performed to document the interactions of striped bass macrophages with some of the Mycobacterium spp. infecting striped bass in Chesapeake Bay. Additional laboratory studies have demonstrated that the severity and progression of the disease is severely impacted by nutritional competency of the fish when challenged with one Mycobacterium (M. marinum) infecting Chesapeake Bay striped bass.

Very little is known regarding the ecology of mycobacteria infecting fish in the Chesapeake Bay ecosystem. We know of no studies in Chesapeake Bay that have attempted to isolate these specific pathogens from water or substrate. The various mycobacterial isolates from fish do show marked temperature preference when grown in vitro.

Nothing is known regarding the impact of mycobacteriosis on striped bass at the population level. The size of the estuarine/marine striped bass population in the Atlantic States is at a record high. There was significant disagreement regarding natural mortality modeling methods used with population data generated through tagging programs administered by the ASMFC in Chesapeake Bay. The results of the modeling may indicate that the natural mortality rate in the spawning component of the striped bass stock had increased dramatically (2x to $3 x$ ) beginning in the late 1990s with a return to historic norms in the lower Bay and a continued elevation in the upper Bay by 2005 . Any relationship between this potential increase in natural mortality and the mycobacteriosis epizootic has yet to be established. 


\section{Scientific Abstracts}

A historical perspective on diseases of striped bass with emphasis on mycobacteriosis .....6

The ecology of mycobacteria infecting striped bass (Morone saxatilis) in Chesapeake Bay: A research plan ................................................................................

Striped bass mycobacteriosis: A zoonotic disease of concern in Chesapeake Bay ................9

Striped bass disease overview for the past ten years plus...................................................10

Survey of gametes and juvenile striped bass (Morone saxatilis) for mycobacteriosis from the Chesapeake Bay: Sampling methods, external lesions, and histopathology.

Microbiology of gametes and age $0-3$ striped bass (Morone saxatilis) ..................................13

Mycobacterial infections in striped bass (Morone saxatilis) from upper and lower Chesapeake Bay: 2002 and 2003 pound net studies .....................................................15

Epizootiology of mycobacteriosis in Chesapeake Bay striped bass (Morone saxatilis): Large-scale field survey............................................................................16

Mycobacteriosis in juvenile Atlantic menhaden ....................................................................17

The influence of dietary intake on the progression and severity of mycobacteriosis in striped bass (Morone saxatilis) ...........................................................................19

Mycobacteriosis in Chesapeake Bay fishes: Perspectives and questions .............................20 Initial investigation of the overall health and presence of mycobacteriosis in Roanoke River, NC, striped bass (Morone saxatilis) ................................................22

Mycobacterial infections in striped bass (Morone saxatilis) from Delaware Bay..................23

Tag-recapture data from Chesapeake Bay striped bass indicate that natural

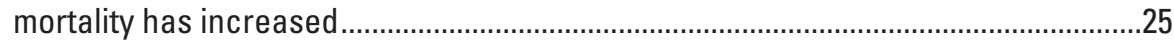

Epizootic mycobacteriosis in Chesapeake Bay striped bass: What is the fate of infected fish? 


\section{A historical perspective on diseases of striped bass with emphasis on mycobacteriosis.}

\begin{abstract}
Eric B. May', John M. Jacobs ${ }^{2}$, and Anthony Overton ${ }^{3}$
'NOAA Living Marine Resources Cooperative Science Center, Department of Natural Sciences, University of Maryland Eastern Shore, Princess Anne, MD 21653; email:ebmay@umes.edu. ${ }^{2}$ NOAA/NOS, National Centers for Coastal Ocean Science, CCEHBR, Cooperative Oxford Laboratory, 904 South Morris Street, Oxford, MD 21654; email: John.Jacobs@noaa.gov. ${ }^{3}$ East Carolina University, Thomas Harriot College of Arts and Sciences, Department of Biology, Howell Science Complex, Greenville, NC 27858.
\end{abstract}

A series of events, beginning in 1985, has preceded this current epizootic of mycobacteriosis in striped bass (Morone saxatilis). With the decline of Chesapeake Bay striped bass stocks and subsequent post-moratorium recovery to record numbers, we have had the opportunity to observe processes that rarely manifest. No recovery of a fishery has been without consequence. We have in Chesapeake Bay the opportunity to examine that consequence and ask if there are indicators suggesting that striped bass have exceeded their carrying capacity. Is this a natural result of an expanding stock that, given patience, will come into balance?

This paper will present a history of striped bass disease in Chesapeake Bay from 1988 to present, including the results of previous conferences that addressed the subject in 2000 and 2003. In the spring and summer of 1988, an outbreak of Streptococcal sp. affecting striped bass, weakfish, and bluefish occurred bay-wide. Sporadic reports of dead striped bass were received by the Maryland DNR Fish Health Program between 1988 and 1994 with isolates of bacteria obtained, primarily gram negative enterics. In this case rafts of dead fish were seen at varying locations from the Bay Bridge-Tunnel to Kent Island. In the spring of 1994 an isolated outbreak involving over 50 fish occurred in the Potomac River at the mouth of the Wicomico River. This outbreak was diagnosed as being the result of Edwardsiella tarda (Baya et al., 1997). In 1995 a second outbreak occurred in the Potomac River; in this case affected fish yielded isolates of Aeromonas sp. and Pseudomonas sp.

Coincident with the Pfiesteria piscicida scare in 1997, striped bass were found to exhibit similar lesions to those seen during previous outbreaks. In this case, however, the lesions were reported throughout the Chesapeake Bay. Isolates of Mycobacterium sp. were derived from spleen and head kidney of fish examined. The severity of the infection often dictated the location of lesions seen. Fish exhibited no external evidence of infections and those with internal lesions were confined to nodules on the spleen, or spleen and liver. In all cases where external lesions were manifest, the spleen and liver were always infected, and in most the head kidney, heart, and gonads were also involved.

In surveys conducted for his doctoral research, Overton et al. (2003) examined 217 striped bass where the fish were necropsied and examined for presence or absence of external and internal evidence of lesions indicative of Mycobacterium sp. infection. This study suggested that there was a relationship between the severity of infection and both size of the fish and condition factor. In all of the cases described above, Mycobacterium sp. was confirmed using acid-fast staining; thus, species identification was not made.

Investigations conducted by NOAA since the 1970s and Maryland DNR scientists since the 1980s have shown that disease in fish resident to the Chesapeake Bay is not a new phenomenon. The presence of epizootics in Chesapeake Bay is also not new; white perch mortalities were observed in the Potomac River in the 1960s and in a variety of fish in 1988. We will also include recent information suggesting that mycobacterial infections have been with us since 1984 or earlier, and that the Edwardsiella tarda epizootic reported in 1994 may have been, in fact, the consequence of Mycobacterium sp.

Two meetings have been held that have addressed the issue, the first on bioenergetics and striped bass (August 2000) and the second specifically addressing Mycobacterium sp. infections in striped bass (April 2004). During the course of these meetings, a list of priority topics was developed which included (ranked in order of importance): (1) Determine the outcome as a result of infection; (2) Determine the spatial extent of the disease; (3) Develop rapid diagnostic method for species of concern; (4) Complete Koch's postulates; (5) Determine mode of transmission; (6) Determine predisposing factors; and (7) Address human health issues. Many of the technical papers in the 2004 meeting touched on the above topics; however, no real conclusions were drawn.

\section{Literature Cited}

Baya, A.M., Romalde, J.L., Green, D.E., Navarro, R.B., Evans, J., May, E.B., and Toranzo, A.E., 1997, Edwarsiellosis in wild striped bass from the Chesapeake Bay: Journal of Wildlife Diseases, v. 33, p. 517-525.

Overton, A.S., Margraf, F.J., Weedon, C.A., Pieper, L.H., and May, E.B., 2003, The prevalence of mycobacterial infections in striped bass in Chesapeake Bay: Fisheries Management and Ecology, v. 10, p. 301-308. 


\section{The ecology of mycobacteria infecting striped bass (Morone saxatilis) in Chesapeake Bay: A research plan.}

\author{
Howard Kator, Martha Rhodes, and David Gauthier
}

Department of Environmental and Aquatic Animal Health, Virginia Institute of Marine Science, College of William and Mary, Gloucester Point, VA 23062; email: kator@vims.edu.

The ecology of mycobacteria in estuarine and marine waters remains poorly understood. The current epizootic in Chesapeake Bay striped bass and newly described pathogens Mycobacterium shottsii and M. pseudoshottsii raise ecological questions that if answered can improve our understanding of the pathogenesis of mycobacteriosis in this fish species. Questions remain whether these mycobacteria are obligate or opportunistic pathogens. Do these species exist as free-living saprophytes in estuarine ecosystems? And if so, is their recent success as pathogens in estuarine systems facilitated by anthropogenic alterations in water quality such as nutrient enrichment or organic pollutants?

The literature describes the environmental occurrence of nontuberculous or environmental mycobacteria using the term "ubiquitous." Numerous research papers on Mycobacterium marinum, for example, contain statements such as

“.......virtually any water source and water-related activity is a potential risk, including tending aquarium, fishing, skin diving, and a number of other water-related activities" (Dobos et al., 1999).

Presence does not necessarily imply function, and from an aquatic microbial ecology viewpoint such statements provide little insight toward resolution of the immediate question raised, e.g., do these organisms participate in processes of energy and material flow or behave essentially as passive and persistent allochthonous particles? A number of recent papers address mycobacterial persistence and dormancy by examining physiological responses to starvation in model species such as $M$. smegmatis. Examples from the literature will be provided in this presentation where appropriate with respect to the following questions:

1. Is there an estuarine reservoir of M. shottsii/pseudoshottsii in Chesapeake Bay?

Ongoing or new research needs to address the question of whether or not the dominant microorganisms now infecting striped bass are autochthonous components of Bay waters or whether they are allochthonous and transient contaminants originating from an external source and happen to infect striped bass. In addition, we need to deter- mine if their distribution is similar to that of M. marinum. Does virtually any source of water serve as a reservoir for the bacterium? And are there animal reservoirs other than striped bass?

2. Are the dominant mycobacteria now infecting striped bass obligate pathogens and not found elsewhere in the environment, or are they opportunistic free-living organisms in Chesapeake Bay habitats?

If recoverable from Bay environments, isolate virulence could be assessed using a fish model or in vitro assays to examine the ability of mycobacteria to invade and persist in primary cultures of host cells or cell lines, as well as cytopathic effect. A recent report suggests that strain variation in $M$. marinum isolates is important to human pathogenicity. Knowing the environmental distribution and prevalence of $M$. pseudoshottsii strains possessing the IS2404 plasmid associated with mycolactone production could be relevant to the epidemiology of the ongoing epizootic.

3. What are some of the basic autecology questions to be addressed for these organisms?

Little is known regarding the autecology of Mycobacterium spp. Some fundamental questions need to be addressed, including the following. How do M. shottsii/ pseudoshottsii respond to physicochemical characteristics of estuarine environments? What are the responses of these species to abiotic factors such as temperature, salinity, and light? What are the effects of nutrients, both inorganic and organic, on growth or survival? Can saprophytic growth occur in filtered estuarine water supplemented with $\mathrm{C}, \mathrm{N}$, and $\mathrm{P}$ or trace elements such as Fe? Can these species utilize hydrocarbons as substrates as can saprophytic mycobacteria found in soils? Is the growth/persistence of these mycobacteria facilitated by nutrient enrichment? Is the mildly alkaline $\mathrm{pH}$ of Bay water detrimental to these organisms? To what extent can persistence under nutrient-limiting conditions be observed with these species? As a null hypothesis, can we assume protracted persistence in vitro in distilled water? What about persistence under environmentally relevant conditions? What are the combined effects of temperature, light, and predation on mycobacterial densities? What are the rates of inactivation/removal that would provide information on temporal boundaries of seasonal infectivity and bacterial survival? Finally, do starved cells demonstrate stress responses similar to those observed in other species of bacteria challenged with adverse conditions? Is there evidence of an adaptive response? Can dormant cells be detected using conventional culture methods? Can dormant cells become viable/infective when conditions improve? 
4. What is the distribution of M. shottsii/pseudoshottsii in Chesapeake Bay aquatic habitats?

What are possible sources? Can M. shottsii/pseudoshottsii be isolated from soils or stormwater runoff? If restricted to water, is their distribution dependent or independent of salinity or rainfall? Can they be isolated from sewage or other types of wastewaters? What is the extent of genomic strain variation among isolates and what genetic mechanisms are involved? Are there subtypes across physicalchemical gradients that vary in virulence?

Other specific niche habitats include microlayer, water column, and biofilms. Microlayers concentrate nonpolar molecules, which may be substrates for mycobacteria. Can these organisms be detected in surface water as well as below seasonal thermoclines? Can they be found in sediment? Biofilms offer unique microenvironments for pathogens and provide protection from predators, enhance potential to achieve high densities, select for virulent strains, and increase the infective dosage. Do swampy freshwater areas contiguous with Bay watersheds provide unique habitats of comparatively low $\mathrm{pH}$ supporting mycobacterial growth?

5. What is the relationship of M. shottsii/pseudoshottsii to other indigenous aquatic microbiota?

Using in situ exposure methods described in the literature, it is possible to evaluate the effect of microbial predation on these species. However, given the recent literature describing how mycobacteria use amoebae as an intracellular refuge for replication, can similar interactions occur with the seasonally diverse estuarine microheterotrophic plankton community? If so, is there potential for mycobacterial transfer up the food chain as a plausible mechanism to infect tertiary consumers such as striped bass?

Although the research questions articulated above are important and relevant, and to some extent testable using conventional cultural methods, it is obvious that efforts to address them will be retarded without improved detection/enumeration techniques.

The classic problem with enumeration of environmental mycobacteria in a mixed microbial community is that existing methods for isolation of mycobacteria employ harsh decontaminants that can significantly bias recovery and render quantitative results inaccurate. Moreover, this limitation becomes more acute should sample concentration be required. There is thus a critical need for improved methods. These include development and validation in environmental waters of species-specific polymerase chain reaction (PCR) primer sets (and TaqMan probes) for real-time PCR quantitative detection. While access to such methods would be extraordinarily beneficial, we cannot ignore that the problem of detecting nonviable cells with PCR will require supplementary approaches to confirm cell viability. Use of live/dead penetrating fluorescent

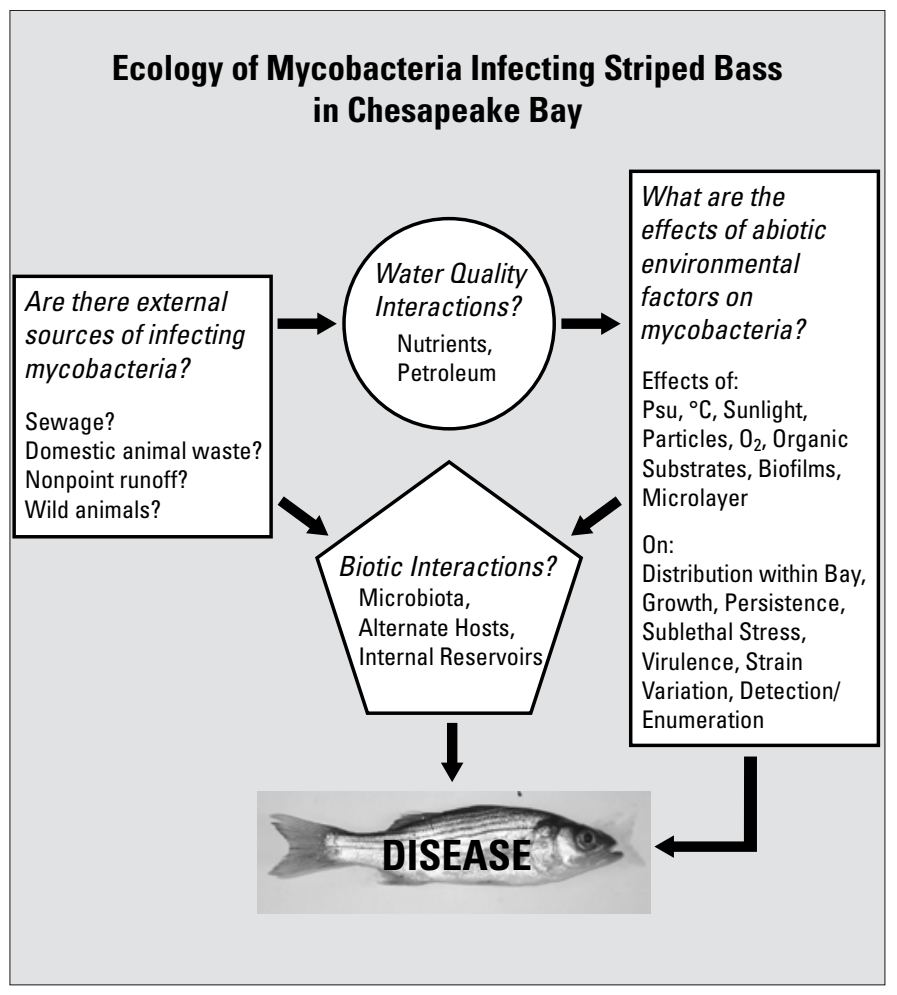

stains, PCRs targeting specific genes or gene products, and perhaps developing a workable fluorescent in situ hybridization (FISH) method combining direct counting with a metabolic assay would facilitate the study of mycobacterial ecology in aquatic systems.

Understanding the ecology of the mycobacteria infecting striped bass is a crucial step toward identifying environmental factors and processes that influence the epidemiology of the current epizootic.

\section{Literature Cited}

Dobos, K.M., Quinn, F.D., Ashford, D.A., Horsburgh, C.R., and King, C.H., 1999, Emergence of a unique group of necrotizing mycobacterial diseases: Emerging Infectious Diseases, v. 5, no. 3, p. 367-378. 


\section{Striped bass mycobacteriosis: A zoonotic disease of concern in Chesapeake Bay.}

\author{
Frank M. Panek ${ }^{1}$ and Tanya Bobo ${ }^{2}$
}

'U.S. Geological Survey, Leetown Science Center, National Fish Health Research Laboratory, 11649 Leetown Road, Kearneysville, WV 25430; email:fpanek@usgs.gov. ${ }^{2}$ Virginia Department of Health, Division of Zoonotic and Environmental Epidemiology, 109 Governor Street, Richmond, VA 23219; email: tanya.bobo@vdh.virginia.gov.

In addition to causing disease in many species of freshwater and marine fishes, there are a few fish pathogens that are known to be zoonotic, that is, causing disease in humans. While the human risk of contracting infection or disease from fish pathogens is generally low, an awareness of the potential risks is important for fishery managers, anglers, and commercial fishers. One of these pathogen groups that is of increasing interest in the Chesapeake Bay Region are the mycobacteria, in particular, Mycobacterium marinum, one of the causative agents of mycobacteriosis in striped bass (Morone saxatilis) and one of the known causes of cutaneous mycobacteriosis in humans.

Recent studies by scientists at the National Fish Health Research Laboratory and the Virginia Institute of Marine Science have shown infection rates in striped bass of up to nearly $62 \%$ in certain Virginia tributaries to Chesapeake Bay (Ottinger et al., 2005). Of the several mycobacteria species known to infect Chesapeake Bay striped bass, several are known to be zoonotic, including $M$. marinum and $M$. fortuitum (Elko et al., 2004). Previous studies have clearly shown that careless handling of infected fish represents a potential health risk to anglers, commercial fishers, and fishery management workers and that resulting localized skin lesion can be very difficult to treat. Immunocompromised individuals can be especially at risk of infection (Glaser et al., 1994).

Surveillance for non-tuberculous mycobacteria (NTM) in Virginia is conducted by the Virginia Department of Health, Division of Disease Prevention. Minimal information is collected on NTM including M. marinum. We were able to compile some limited reported cases of $M$. marinum for the years 2000 - 2005 from 17 reporting districts within the tidal Chesapeake Bay watershed of Virginia. Similar epidemiological data were also available from the Maryland Department of Health and Mental Hygiene. In this instance, the Division of Medical Microbiology provided a summary of laboratory reports from clinical specimens, sorted by the 10 counties bordering Chesapeake Bay, from 1995 - 2005. Data from both states included age, sex of the patient, and the location or nature of the infection (e.g., finger, hand, foot). Neither state was able to provide information regarding the mechanisms of injury/infection or provide any information on the patient's occupation. We compiled similar data from counties outside Chesapeake Bay within both states in order to contrast the incidence of cutaneous mycobacteriosis cases in Bay counties to the general population at large. In Virginia, we examined the database of reportable communicable diseases from the Central Shenandoah (10 counties) and Central Virginia (6 counties) Districts, from 2000 - 2005. In Maryland, we examined records from Allegheny and Garrett Counties. In all instances, the case numbers reported are raw data not corrected for population size.

During a period from 1995-2005, the States of Virginia and Maryland documented 275 cases of M. marinum infections in the human population within the Bay watershed. These cases represent a significant increase from earlier investigations regarding NTM disease. A national survey involving 46 state and local laboratory centers from 33 states and the District of Columbia in 1981-1983 documented a national average of about 40 cases per year (O'Brien et al., 1987). A similar laboratory-based survey initiated in 1993 documented an annual national average incidence of about 158 cases with most of these reported in the southeast (Dobos et al., 1999). In Maryland, the largest number of cases came from Ann Arundel $(n=106)$ and Talbot $(n=51)$ Counties. In Virginia, the majority of cases originated in the Rappahannock $(n=10)$, Peninsula $(\mathrm{n}=8)$, and Three Rivers $(\mathrm{n}=8)$ reporting districts. The trend in reporting shows increases in the fall and winter months with the lowest reporting indices in the early spring in both states. Most of those infected were males (67\%-VA; 67\%-MD) between the ages of 40 and 70 (79\%-VA; 62\%-MD) and most infections were on hands and fingers (43\%-VA; 63\%-MD). During the same period, only four cases of $M$. marinum infection were noted in non-Bay counties in both states.

In this paper we discuss the incidence and prevalence of mycobacterial infections in striped bass and contrast these to epidemiological data collected by the Virginia Department of

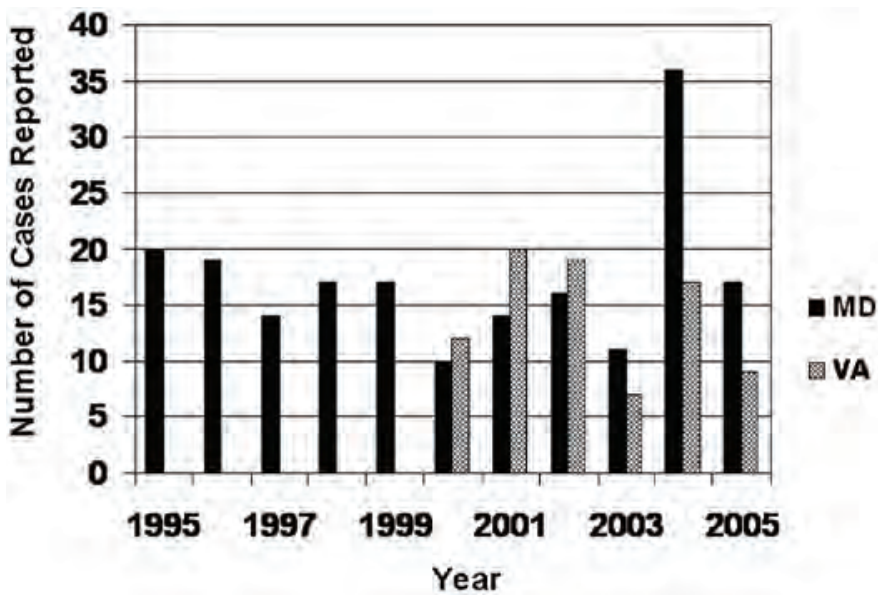

Number of reported human cases of cutaneous mycobacteriosis in Maryland and Virginia, 1995-2005 
Health and the Maryland Department of Health and Mental Hygiene of the occurrence of cutaneous mycobacteriosis in the human population in the tidal Chesapeake Bay drainage. While we are unable to demonstrate any cause-and-effect relationships between the epizootic of mycobacteriosis in striped bass and the occurrence of higher than normal incidences of NTM cutaneous infections in the human population of the Bay counties, the weight of evidence suggests reason for concern. Therefore, we recommend that State and Federal fishery management authorities work with public health officials to increase awareness on the part of fishery workers, anglers, and commercial fishers on the potential risks of mycobacterial infections. Fishery workers, including management biologists and researchers, should not handle infected striped bass if they have cuts, abrasions, or sores on hands. We recommend that individuals handling or processing fish utilize basic precautions such as wearing gloves and properly washing hands after handling fish. Individuals that are immunocompromised should seek medical direction before working with infected fish.

\section{Literature Cited}

Dobos, K.M., Quinn, F.D., Ashford, D.A., Horsburgh, C.R., and King, C.H., 1999, Emergence of a unique group of necrotizing mycobacterial diseases: Emerging Infectious Diseases, v. 5, no. 3, p. 367-378.

Elko, L.E., Rosenbach, K., and Sinnott, J., 2004, Cutaneous manifestations of waterbourne infections: Current Infectious Disease Reports, v. 5, p. 398-406.

Glaser, C.A., Angulo, F.J., and Rooney, J.A., 1994, Animal associated opportunistic infections among persons infected with the human immunodeficiency virus: Clinical Infectious Disease, v. 18, p. 14-24.

O’Brien, R.J., Geiter, L.J., and Snider, D.E., 1987, The epidemiology of nontuberculous mycobacterial diseases in the United States: Amer. Rev. Resp. Disease, v. 135, p. 1007-1014.

Ottinger, C.A., Blazer, V.S., Densmore, C. L., Gauthier, D.T., Kator, H., Panek, F.M., Rhodes, M.W., and Vogelbein, W., 2005, Mycobacteriosis in Chesapeake Bay Striped Bass (Morone saxatilis), in: Cipriano, R.C., Shchelkunov, I.S., and Faisal, Mohamed, eds., Health And Diseases Of Aquatic Organisms: Bilateral Perspectives: East Lansing, Michigan, Michigan State University Press, p. 238-243.

\section{Striped bass disease overview for the past ten years plus.}

\author{
Laurence Pieper
}

Maryland Department of Natural Resources, Fisheries Service, 301 Marine Academy Drive, Stevensville, MD 21666; email: lpieper@dnr. state.md.us.

Ulcerative dermatitis syndrome (UDS) was described by Sindermann (1988) as caused by multiple species of bacteria in many species of fish in saltwater, estuarine, and freshwater ecosystems. Bacterial infections have been documented by many researchers; these infections cause fish lesions internally and externally. Snieszko (1978) reported on mycobacteriosis in fish and described a new species found by Ross in salmonids. Sakanari (1983) reported mycobacteriosis in striped bass in the San Francisco Bay on the West Coast. In this case the disease results in annual mortality.

In 1988 Streptococcus iniae was isolated as the causative agent in fish kills in the lower Chesapeake Bay of Maryland. Many species were involved: striped bass, bluefish, sea trout, red drum, croaker, and spot. We found the infection in bluefish by filleting the fish whereupon pus was found along the backbone and in the red musculature area along the dorsal. The source for this disease was never ascertained; however, this pathogen caused widespread mortality to multiple species. This textbook event is what fish pathologists would expect: an end result to the disease investigation.

In 1994 a new incident occurred where pound net fishermen from the Choptank and Potomac Rivers reported striped bass with lesions. The Aquatic Animal Health (AAH) group responded to these reports and transported fish to the Maryland Department of Agriculture's (MDA) Animal Health Laboratory in College Park, Maryland. Edwardsiella tarda was isolated from the fish. The superficial lesions associated with the infection were hemorrhagic and bilateral on the fish. The AAH personnel went to reinvestigate the problem in subsequent years (1995-1996). A sampling protocol was initiated: a total of 10-12 symptomatic fish and 2-3 normal control fish were collected at each site per trip and delivered to the MDA Animal Health Laboratory in College Park, Maryland. E. tarda could not be found in all the fish collected; however, many other bacterial agents were found. Some of the genuses were Aeromonas, Pseudomonas, Streptococcus, and Vibrio to mention a few, all of which were isolated from striped bass exhibiting lesions.

Field sampling for 1997 coincided with the Maryland Department of Natural Resources (MDNR) Striped Bass Stock Assessment (SBSA) fall tagging survey, which takes place during the fall striped bass season in the Chesapeake Bay. 
Fish were collected from pound nets located at Tall Timbers in the Potomac River; the main bay north of Point Lookout, Kent Island; and an area near Rock Hall, Maryland. The sampling protocol continued and fish were collected at each site per trip and delivered to MDA Animal Health Laboratory in College Park, Maryland. The lesions on the fish were of a different characteristic than those seen in 1994-1995; early in the sampling $15-20 \%$ of the striped bass had severe erosive lesions and the dermis more eroded on many of the fish to the point that the muscle layer was visible. Later in the fall signs of healing were seen on some fish and the number of individuals showing lesions had diminished significantly (5-10\%), perhaps due to the drop in water temperature. Histological results revealed that the fish with lesions and control fish had granulomas in the spleen, anterior kidney, and liver. A gram stain of the histological slides revealed gram positive cocci; an acid-fast stain revealed acid-fast positive rods in many of the granulomas in the spleen, head kidney, and liver. The MDA Animal Health Laboratory in College Park, Maryland, isolated $S$. iniae and a new species of mycobacterium, M. chesapeakii. The incident is distinct because the disease is species specific and caused no mortality, unlike the 1988 streptococcus event.

The Fish and Wildlife Health (FWH) program of the MDNR in 1998 changed the sampling protocol to a modified random sampling design, which is used to the present time. The first 10 fish out of the pound net were collected for examination. Additionally, the sampling design was expanded and striped bass were collected from gill net and hook and line surveys. External lesions were no longer erosive and severe in nature but had returned to the superficial nature seen previous to 1997 . Some individual fish manifested few or no external signs of disease. In advanced stages, though, emaciation, exophthalmia, hemorrhagic and dermal ulcerative lesions, or loss of scales may be observed. The prevalence of emaciation increased in 1998 and 1999; however, in 2000 the rate of emaciated individuals decreased and to date has not been observed at the previous level.

The observed infection rate of mycobacteriosis has increased over the past 5 years to a high of $62 \%$ of the fish examined. Additionally, streptococcus, vibrio, micrococcus, and enterococcus have been isolated. This array of bacteria has been causing a multiple infection for the fish and the immune system of these individuals must be challenged. Observed overall condition of the fish has improved slightly and not as many emaciated fish have been seen; lesion prevalence has dropped to $5 \%$. There is still no mortality associated with this disease syndrome, unlike the textbook cases from 1988 and 2000.

This disease of striped bass has eluded researchers to date. At present there is no textbook event associated with this disease. The specific cause has not been identified, yet researchers have identified numerous genera of bacteria involved and numerous species of some genera found associated with affected fish. The effect has been identified with numerous clinical signs: emaciation, exophthalmia, hemorrhagic and dermal ulcerative lesions, internal lesions, para- sites, and lesions and granulomas in internal organs. Yet, no end result from this disease can be declared at this point. There is no direct evidence of mortality associated with mycobacteriosis or ulcerative dermatitis syndrome.

What we know:

- External lesions may or may not be present and are not always indicative of mycobacteriosis; lesion prevalence has dropped to $5 \%$.

- Multiple infections with other bacteria present internally along with mycobacteriosis.

- Mycobacteriosis prevalence is up from 1998 to $62 \%$ in 2005 and is species specific.

- There is no mortality associated with this mycobacteriosis infection, unlike that on the West Coast.

- Striped bass population is at an all-time record high. Disease could be an indication of an overpopulation problem and an insufficient forage base.

\section{Literature Cited}

Sakanari, J. A., Reilly, C.A., and Moser, M., 1983, Tubercular lesions in pacific coast populations of striped bass: Transactions of the American Fisheries Society, v. 112, p. 565-566.

Sindermann, C.J., 1988, Epizootic ulcerative syndromes in coastal/estuarine fish: NOAA Technical Memorandum NMFS-F/NEC-54.

Snieszko, S.F., 1978, Mycobacteriosis (Tuberculosis) of fishes: U.S. Fish and Wildlife Fish Disease Leaflet 55, p. 1-9. 


\section{Survey of gametes and juvenile striped bass (Morone saxatilis) for mycobacteriosis from the Chesapeake Bay: Sampling methods, external lesions, and histopathology.}

\author{
Mark A. Matsche1, Lawrence Pieper², Cynthia B \\ Stine ${ }^{3}$, Andrew Kane ${ }^{3}$, Ana Baya ${ }^{4}$, Kevin Rosemary², \\ Cindy Driscoll ${ }^{2}$, and John M. Jacobs ${ }^{5}$.
}

\begin{abstract}
'Maryland Department of Natural Resources, Cooperative Oxford Laboratory, 904 South Morris Street, Oxford, MD 21654; email: mmatsche@dnr.state.md.us, krosemary@dnr.state.md.us,cdriscoll@ dnr.state.md.us. ${ }^{2}$ Maryland Department of Natural Resources, Fisheries Service, 301 Marine Academy Drive, Stevensville, MD 21666; email: lpieper@dnr.state.md.us. ${ }^{3}$ Aquatic Pathobiology Center, University of Maryland, Department of Veterinary Medicine, 8075 Greenmead Dr., College Park, MD 20742; email: cstin001@umaryland.edu,akane@ umaryland.edu. ${ }^{4}$ Maryland Department of Agriculture Animal Health Laboratory, 8077 Greenmead Drive, College Park, MD 20742; email: ambaya@umd.edu. ${ }^{5} \mathrm{NOAA} / \mathrm{NOS} / \mathrm{Cooperative} \mathrm{0xford} \mathrm{Laboratory,} 904$ South Morris Street, Oxford, MD 21654; email:John.Jacobs@noaa.gov.
\end{abstract}

A survey of striped bass (Morone saxatilis) in the Chesapeake Bay since 1998 has revealed the prevalence of mycobacterial infection from $25-60 \%$. Surveyed fish were collected primarily from commercial pound nets and were generally 3 years old or older. While this survey provides a useful index of disease in the harvestable segment of the population, information on younger fish is lacking. To fill this gap, we initiated a study to provide data from age 0-3 fish. In addition, gamete samples from ripe striped bass were collected for mycobacterial primary isolation to examine the possibility of vertical transmission.

Gametes were collected from ripe fish from the Nanticoke and Choptank Rivers in 2003-04 for assessment of the presence of Mycobacterium sp. Sixty fish (30 males, 30 females) were collected by electro-fishing from each river during the month of April. Stunned fish were netted from the river and transferred to a holding tank containing tricaine methanosulfonate (MS222) for sedation. The vent of each fish was disinfected with $70 \%$ ethyl alcohol (ETOH) prior to collection of gametes. From each male, approximately $15 \mathrm{~mL}$ of milt was expressed directly into sterile Falcon centrifuge tubes. From each female, approximately $5 \mathrm{~mL}$ of eggs were collected using modified 5-mL sterile serological pipettes. The tip of each pipette was broken off, the filter media was removed, and the blunt end was disinfected with 70\% ETOH and inserted into the vent, and light suction was applied. Gamete samples were transported chilled to the Cooperative Oxford Labora- tory (COL), frozen, and shipped to the University of Maryland Aquatic Pathobiology Center (APC) for bacterial culture.

Juvenile fish from three areas of Maryland's portion of the Chesapeake Bay, including the upper Bay, the lower Choptank River, and the lower Potomac River, were surveyed for mycobacteria infection. Young-of-year (YOY) fish were collected by beach seine from at least two sites from within each area. YOY fish from the upper Bay were collected from sites in the lower Sassafras River. Thirty fish were collected from each site and transported live to the APC for necropsy. The examination included: gross lesion incidence; parasite abundance; bacterial culture of brain, liver, and anterior kidney; and mycobacterial culture from spleen. Thirty additional fish collected from each site were transported live to COL, sacrificed with an overdose of MS222, and necropsied, and tissue samples were preserved in $10 \%$ neutral buffered formalin. Fish of each age class ( 1 through 3 ) were collected from each area by hook-and-line, transported to either the APC or COL, and processed as previously described. Upper Bay fish were collected from an area called "Love Point," which is bounded by the mouth of the Chester River and main stem of the Bay.

Preserved fish tissues were processed for routine histology and stained with haematoxylin and eosin. Adjacent tissue sections were stained using aqueous acid-fast for acid-fast bacteria. Samples of spleen, liver, and anterior kidney were collected aseptically and processed for bacterial culture. Spleen, liver, and anterior kidney were chosen for culture based on results from previous striped bass surveys conducted from 1998-2002; $98 \%$ of these fish examined were positive for mycobacteria in at least one of these organs.

The prevalence of external lesions on fish in 2003 was $2.3 \%(\mathrm{~N}=43)$ for age- 1 fish, $1.8 \%$ for age- 2 fish, and $0 \%$ $(\mathrm{N}=24)$ for age-3 fish. In 2004, the prevalence of external lesions was $12.0 \%$ for age-1 fish ( $\mathrm{N}=184)$ and $13.2 \%$ for age-2 fish $(\mathrm{N}=174)$.

In analysis, fish were considered to be positive for mycobacteria if acid-fast bacilli were evident in granulomas from any tissue. In all age classes, granulomas were occasionally observed that contained visible elements of parasites, non-specific staining from acid-fast procedure, or no acid-fast bacilli. Severity of infection was assessed by number of organs with granulomas containing acid-fast bacilli per organ: 1 - focal granuloma, 2- two to six granulomas, and 3-more than six granulomas.

Prevalence of mycobacteria, detected by acid-fast positive granulomas, was compared by age and gender as well as age and location. Analysis consisted of $2 \times 2$ contingency table tests for homogeneity, with the Yates-corrected chi-square test if there was a large enough sample size $(\mathrm{N}$ for each cell $>5$ ) or Fisher's exact test for binomials ( $\mathrm{N}$ of at least one cell $<5$ ).

No granulomas containing acid-fast bacilli were detected in YOY collected in $2003(\mathrm{~N}=212)$ or $2004(\mathrm{~N}=213)$. In 2003 and 2004, no differences were detected in prevalence of mycobacteria by region or gender in age- 1 through age- 3 fish. In 2003, Bay-wide prevalence of mycobacteria was $16 \%$ for age- $1(\mathrm{~N}=43), 24 \%$ for age- $2(\mathrm{~N}=112)$, and $25 \%$ for age- 3 
$(\mathrm{N}=24)$ fish. Analysis of prevalence by age class (Fisher exact test) indicated that prevalence of mycobacterial infection was significantly lower in age-0 fish than all other age classes.

No differences in prevalence of mycobacterial infection were detected however, between age-1, age-2, and age- 3 fish, which may be the result of low sample sizes. In 2004, Bay-wide prevalence of mycobacteria was $13 \%$ for age- $1(\mathrm{~N}=184)$, $20 \%$ for age- $2(\mathrm{~N}=174), 57 \%$ for age- $3(\mathrm{~N}=7)$, and $73 \%$ for age-4 $(\mathrm{N}=11)$ fish. Analysis indicates that mycobacterial infection was significantly lower in prevalence in age- 0 fish than all other age classes, and that age- 3 and age- 4 fish were significantly higher in prevalence than age- 1 and age- 2 fish. No difference was detected between age- 1 and age- 2 fish, or between age- 3 and age- 4 fish. There was an insufficient number of parasite observations from fish collected in 2003 and 2004 to allow comparisons to be made between infected and uninfected fish.

Severity of infections was characterized by organ involvement. In 2003, of fish with organ involvement ( $\mathrm{N}=41)$, granulomas with acid-fast bacilli were evident in $82.9 \%$ of spleens, $39.0 \%$ of anterior kidneys, and $19.5 \%$ of livers. In 2004, this trend generally continued as granulomas were observed in $85.0 \%$ of spleens $(\mathrm{N}=71), 54.0 \%$ of anterior kidneys $(\mathrm{N}=70)$, and $14.0 \%$ of livers $(\mathrm{N}=71)$. The average number of organs involved in infected fish in 2003 was 1.6 for age- 1 and 1.4 for age- 2 fish. The average ranking of numbers of granulomas with acid-fast bacilli in infected organs was 0.67 for age-1, 1.02 for age-2, and 0.83 for age-3 fish in 2003 . In 2004 , average rank was 1.1 for both age- 1 and age- 2 fish.

In summary, mycobacteria were first detected in age-1 fish by histopathology. Histological data suggest a trend of increasing prevalence of mycobacteria infection with age, although significant differences were not detected between all age classes. Prevalence of infection among juvenile striped bass does not differ by gender or region in Maryland's portion of the Chesapeake Bay. Infection is most evident in spleen, then anterior kidney, and then liver. The incidence of external lesions appears very similar among age 1-3 striped bass.

\section{Microbiology of gametes and age 0-3 striped bass (Morone saxatilis).}

\author{
Cynthia B. Stine ${ }^{1,2}$, Andrew S. Kane $e^{1,2,3}$, Mark \\ Matsche ${ }^{4}$, Larry Pieper ${ }^{4}$, Kevin Rosemary ${ }^{4}$, John M. \\ Jacobs $^{5}$, John Abel ${ }^{6}$, Cindy Driscoll ${ }^{4}$, Ana M. Baya ${ }^{2,6}$
}

'Aquatic Pathobiology Center, University of Maryland, 8075 Greenmead Drive, College Park, MD 20742; email: cstin001@umaryland.edu, akane@umaryland.edu. ${ }^{2}$ Department of Veterinary Medicine, University of Maryland, 8075 Greenmead Drive, College Park, MD 20742. ${ }^{3}$ Department of Epidemiology and Preventive Medicine, University of Maryland School of Medicine, Baltimore, MD. ${ }^{4}$ Maryland Department of Natural Resources/Cooperative Oxford Laboratory, 904 South Morris Street, 0xford, MD 21654; email: MMatsche@ dnr.state.md.us,_LPieper@dnr.state.md.us,KRosemary@dnr.state. md.us,CDriscoll@dnr.state.md.us. ${ }^{5} \mathrm{NOAA} / \mathrm{NOS} /$ Cooperative 0xford Laboratory, 904 South Morris Street, Oxford, MD 21654; email: John. Jacobs@noaa.gov. ${ }^{6}$ Maryland Department of Agriculture Animal Health Laboratory, 8077 Greenmead Drive, College Park, MD 20742; email:jmiltabell@aol.com,ambaya@umd.edu.

Mycobacteriosis in Chesapeake Bay striped bass (Morone saxatilis) was first reported in 1997. Recent reports indicate that up to $76 \%$ of fish can be infected with mycobacteria in certain regions of the Bay. However, infection prevalence is believed to increase with age and published studies have concentrated on prevalence in older fish. This study examined the prevalence of mycobacterial infection in gametes and 0-3 year old striped bass, and was designed to identify possible risk factors associated with mycobacterial infection.

Gametes from ripe/spawning males and females were non-destructively collected in the field using a sterile catheter from spawning stock in the Choptank and Nanticoke Rivers in 2003 and 2004. Young-of-the-year striped bass were collected by beach seine in the upper Bay and the Choptank, Nanticoke, and Potomac Rivers in 2003 and 2004, and in the Pocomoke River in 2004. Older (1-3 year old) fish were collected by hook and line from the upper Bay and the Choptank and Potomac Rivers in 2003 and 2004, and by pound net in the Pocomoke River in 2004. Live fish were transported to the laboratory for aseptic necropsy with observations taken on gross pathology and parasitology, and samples taken for general bacteriology, mycobacterial culture, and histology.

Samples of brain, liver, and anterior kidney were used to inoculate 1\% Tripticase Soy Broth (TSB) and 1\% Tripticase Soy Agar (TSA). Growth in TSB was streaked on TSA for isolation and identification. Resulting colonies were identified by routine bacteriology, biochemical reactions within analytical profile index strips, and fatty-acid methyl ester (FAME) analysis by capillary gas chromatography. Portions of spleens were aseptically removed for mycobacterial isolation. Spleens 
were homogenized in Tris-EDTA buffer, diluted in BPBS, and plated on Middlebrook agar supplemented with oleic acid, albumin, dextrose, and catalase enrichment. Plates were checked for growth every week for 8-12 weeks. Colonies with morphology consistent with mycobacteria were tested for Ziehl-Neelson acid-fastness. Characteristic acid-fast positive colonies were streaked for isolation on Middlebrook agar, and when sufficient growth occurred, were analyzed by gas chromatography FAME analysis for putative species identification. Gametes were processed for mycobacterial isolation as described for splenic tissue as $0.5 \mathrm{~mL}$ of gametes were homogenized in $2 \mathrm{~mL}$ BPBS.

Gametes sampled in 2003-2004 were infected with mycobacteria, Pseudomonas fluorescens, Micrococcus spp., and unidentified yeast. Prevalence data for these findings are presented below (sample sizes in parentheses).

\begin{tabular}{c|ccc|cc}
\hline \multirow{2}{*}{ Area } & \multicolumn{3}{|c|}{$\mathbf{2 0 0 3}$} & \multicolumn{2}{c}{2004} \\
\cline { 2 - 6 } & Myco & Yeast & $\begin{array}{c}\text { P. Fluo- } \\
\text { rescens }\end{array}$ & Myco & $\begin{array}{c}\text { Micro- } \\
\text { coccus }\end{array}$ \\
\hline Choptank & $3(65)$ & $22(65)$ & $8(65)$ & $2(52)$ & $8(52)$ \\
Nanticoke & $11(62)$ & $5(62)$ & $2(62)$ & $5(60)$ & $0(60)$ \\
\hline
\end{tabular}

A difference between rivers was found in the prevalence of the yeast in 2003 ( $\mathrm{p}=0.008$ ) and the Micrococcus spp. in $2004(\mathrm{p}=0.04)$. No gender difference was found with any of the putative pathogens. Neither the yeast, nor P. fluorescens, nor the Micrococcus spp. was identified as a risk factor for mycobacterial infection by statistical tests for homogeneity.

Young-of-the-year striped bass were also infected with mycobacteria. One fish from the upper Bay $(\mathrm{N}=60)$ was positive in 2003. In 2004, one fish from the upper Bay $(\mathrm{N}=60)$ and one from the Choptank $(\mathrm{N}=60)$ were positive. Additionally, $25 \%$ of young-of-the-year striped bass from the Pocomoke $(\mathrm{N}=12)$ were positive. The young-of-the-year collected in the Pocomoke River had a higher prevalence than those collected in the other areas combined $(\mathrm{p}=0.0008)$. General microbiology results indicated that a notable proportion of these youngof-the-year fish were positive for other bacterial pathogens, including Photobacterium damsela, Pleisomonas shigelloides, Aeromonas hydrophila, and several Vibrio species.

One-year-old striped bass appeared to have the highest prevalence of cultureable mycobacteria in all rivers sampled (see prevalences in table below; sample sizes in parentheses).

No differences among rivers were found within age groups in 2003, and analysis by age indicated 1 year olds were over seven times more likely to be infected with culturable

\begin{tabular}{ccccc}
\hline Area & Year & Age 1 & Age 2 & Age3 \\
\hline Choptank & 2003 & $22(37)$ & $14(59)$ & $8(12)$ \\
& 2004 & $13(23)$ & $6(16)$ & - \\
Potomac & 2003 & $0(5)$ & $0(1)$ & $0(10)$ \\
& 2004 & $0(19)$ & $0(14)$ & - \\
Upper Bay & 2003 & $33(3)$ & $9(44)$ & $0(15)$ \\
& 2004 & $27(11)$ & $11(18)$ & $0(1)$ \\
Pocomoke & 2004 & $53(17)$ & $33(6)$ & $0(2)$ \\
\hline
\end{tabular}

mycobacteria than 3 year olds $(\mathrm{p}=0.02)$. No differences among rivers were found within 2- and 3-year-old fish in 2004.

However, the prevalence in 1-year-old fish in the Potomac was lower than that in the upper Bay $(\mathrm{p}=0.04)$ and the Pocomoke River ( $p=0.0003$ ). These differences prevent collection-wide age analysis for 2004. Parasite or gross pathology observations were not found to be risk factors for infection with mycobacteria. General microbiology results indicated that, other than mycobacteria, 1-3 year old striped bass harbor fewer bacterial pathogens compared with young-of-the-year striped bass.

Preliminary results indicate that sampling both anterior kidney and spleen tissue, versus sampling only one organ, provides optimal identification of mycobacteria culture-positive fish (observed agreement $=0.80$ ). Additionally, the gonads of this age group (1-3 year olds) do not appear to be infected with mycobacteria.

The FAME analyses used for general bacterial identification and preliminary mycobacterial speciation are part of the Sherlock Microbial Identification System (MIDI Inc., Newark, $\mathrm{DE}$ ), an automated method of bacterial speciation used in conjunction with gas chromatography. However, a large majority of environmental mycobacteria are not in the database. Since 1999, our laboratory has amassed over 600 mycobacterial samples isolated from wild, aquarium, and aquacultured fish in Maryland. Based on chromatograms from these isolates, our laboratory has been able to create a dendogram (i.e., visual clusters) of these mycobacterial isolates based on possible species groupings. Preliminary analyses have identified a portion of these isolates as $M$. marinum, $M$. fortuitum, $M$. chelonae, M. gordonae, M. szulgai, M. scrofulaceum, $M$. interjectum, $M$. triplex, M. septicum, M. rhodesia, M. duvalii, M. poriferae, and the M. chesapeakii-shottsii-pseudoshottsii complex. This method, still under development, allows unknown samples to be tracked and matched against existing known samples for identification, and may be instrumental in following specific mycobacterial strains in future epidemiologic studies.

In summary, microbiology data suggest that juvenile striped bass are minimally infected with mycobacteria, whereas up to $50 \%$ of 1-3 year olds in certain areas can be infected. Excluding the young-of-the-year fish, prevalence of culturable mycobacterial infection within sampled areas tends to decrease with age, which is contrary to prevalence data based on the presence of granulomas with acid-fast bacteria. Gas chromatography FAME analyses indicate Chesapeake Bay striped bass are infected with several species of mycobacteria, as are other wild-caught Chesapeake Bay fish species. Additionally, young-of-the-year striped bass carry several bacterial pathogens other than mycobacteria, whereas 1-3 year olds are relatively free of such pathogens. Currently, no risk factors have been associated with mycobacterial infection in this preliminary analysis.

Support for this study was provided by the Maryland Agriculture Experiment Station (MAES), the National Oceanic and Atmospheric Administration (NOAA), the Maryland Department of Health and Mental Hygiene, and the Centers for Disease Control and Prevention (CDC). 


\section{Mycobacterial infections in striped bass (Morone saxatilis) from upper and lower Chesapeake Bay: 2002 and 2003 pound net studies.}

\section{Christopher A. Ottinger}

U.S. Geological Survey, Leetown Science Center, National Fish Health Research Laboratory, 11649 Leetown Road, Kearneysville, WV 25430; email:cottinger@usgs.gov.

In the fall of 2002 and 2003 striped bass were obtained from commercial pound nets located at the mouths of the Nanticoke (11/22/2002, 11/3/2003), Potomac (11/21/2002, 11/6/2003), Rappahannock (11/8/2002, 11/6/2003), and York Rivers (11/14/2002, 11/12/2003). Fifty fish were obtained in each sample. Nets were fished for approximately $24 \mathrm{~h}$. Live striped bass were removed from the nets and transported to shore in a water tank fed by pumped surface water. Prior to necropsy, fish were weighed and measured for total length. Spleen portions were aseptically removed for bacterial culture. Following necropsy, fish were eviscerated and weighed for condition factor calculation ( $\mathrm{K}=$ (eviscerated weight/total length $\left.{ }^{3}\right) \times 10^{4}$; Clark, 1927). Recovery of bacteria from aseptically harvested spleen portions was performed as described by Rhodes et al. (2004) following the protocol for aseptically sampled internal sites in fish. Unlike in the procedure described by Rhodes et al. (2004), culture plates were not duplicated. Homogenates were diluted 10-fold in Butterfield's dilution buffer and $200 \mu \mathrm{L}$ aliquots of the original homogenate and dilutions were plated on Middlebrook agar for colony enumeration and primary isolation. In 2002, the dilution series was determined based on the presence of granulomas in the spleen as seen in macroscopic examination. When granulomas were present, dilutions were made through $1 \times 10^{4}$. Dilutions were made to $1 \times 10^{2}$ when granulomas were not observed. In 2003 all dilution series were made through $1 \times 10^{4}$. The acid-fast bacilli insolated in 2003 were characterized using the bacteriologic biochemical methods described by Rhodes et al. (2004). The acid-fast bacilli isolated in 2002 were not characterized. Individual spleen mycobacterial infection was indicated by a positive bacterial culture. Prevalence of infection was defined as the percentage of individuals in a sample that exhibited colonies of acid-fast bacilli in spleen cultures. Intensity of bacterial infection was defined as the number of colony forming units (CFU) $\mathrm{g}^{-1}$ spleen. Differences among sample total length and condition factor were evaluated by analysis of variance (ANOVA) with pair-wise post hoc (Tukey) comparisons where appropriate. Differences among sample mycobacterial infection intensities were evaluated using cross tabulation $(2 \mathrm{x} 4)$ with Pearson chi-square. Bacterial infection intensity was evaluated using Kruskal-Wallis one way analysis of variance. Differences were considered statistically significant when $p \leq 0.05$. Sample size for the mycobacteria cultures was reduced as a result of plates lost from overgrowth by non acid-fast organisms. Only data sets that included culture results were included in data analysis. In some instances, colony numbers were too numerous to count. Data for these fish were included in the determination of infection prevalence but not infection intensity. Data were pooled for the upper (Nanticoke, Potomac) and lower (Rappahannock, York) Bay.

In 2002, striped bass total length ( $\mathrm{n}$, mean $\pm \mathrm{SD}$ ) for the upper (80, 475.6 \pm 59.7$)$ and lower (76, 529.1 \pm 59.2$)$ Bay were significantly different. The condition of all fish analyzed was significantly higher in the upper Bay $(79,0.830 \pm .097)$ than the lower (76, $0.787 \pm .097)$. Mycobacterial infection prevalence (n, percent) for the upper $(80,46.2 \%)$ and lower $(76,41.3 \%)$ Bay was not significantly different. Infection intensity (n, median CFU) for the upper $(35,52,200)$ and lower $(32,40,500)$ Bay was not significantly different. In both the upper and lower Bay, mycobacteria infected fish had significantly reduced condition relative to noninfected fish from the same area $(\mathrm{n}$, mean \pm SD: upper infected $=0.801 \pm 0.098$; upper noninfected $=0.857 \pm 0.089$; lower infected $=0.747 \pm$ 0.093 ; lower noninfected $=0.816 \pm 0.091$ ). There was no significant difference in the length of infected versus noninfected striped bass in either region. In the 2003 samples, striped bass total length $(\mathrm{n}$, mean $\pm \mathrm{SD})$ for the upper $(75,452.7 \pm 75.2)$ and lower $(89,504.5 \pm 83.9)$ Bay were significantly different. The condition of all fish analyzed was significantly lower in the upper Bay $(75,0.849 \pm .117)$ than the lower $(89,0.956 \pm$ .099). Mycobacterial infection prevalence (n, percent) for the upper $(75,68.0 \%)$ and lower $(89,62.9 \%)$ Bay was not significantly different. Infection intensity (n, median CFU) for the upper $(51,160200)$ and lower $(56,18500)$ Bay was significantly different. In the upper Bay, mycobacteria infected fish had significantly reduced condition relative to noninfected fish $(\mathrm{n}$, mean $\pm \mathrm{SD}$ : infected $=51,0.814 \pm 0.119$; noninfected $=24$, $0.926 \pm 0.066)$. The condition of mycobacteria infected striped bass $(\mathrm{n}$, mean $\pm \mathrm{SD})$ from the lower Bay $(56,0.955 \pm 0.088)$ was not significantly different from that of the noninfected fish $(33,0.957 \pm 0.116)$. There was no significant difference in the length $(\mathrm{n}$, mean $\pm \mathrm{SD})$ of infected $(56,517.0 \pm 84.6)$ versus noninfected $(33,483.3 \pm 79.5)$ striped bass in the lower region. In the upper region of the Bay the infected fish $(n$, mean \pm SD) were significantly larger $(51,477.7 \pm 75.0)$ than noninfected fish $(24,399.6 \pm 40.5)$. Characterized mycobacteria from the 2003 samples were predominantly (prevalence and intensity) Mycobacterium shottsii in both the upper and lower regions of the Bay.

Results from the fall 2002 and 2003 samples suggest some annual variation in mycobacterial infection. Differences were observed between regions of the Bay with the most prominent difference observed in 2003. As previously reported (Overton et al. 2003), infection maybe associated with reduced 
condition factor and larger fish may have a greater probability of being infected (Overton et al. 2003, Rhodes et al. 2004). Although multiple Mycobacterium spp. were infecting the striped bass sampled, Mycobacterium shottsii was the most prominent species.

\section{Literature Cited}

Clark, F.N., 1927, The weight-length relationship of the California sardine (Sardina caerulea) at San Pedro: California Division of Fish and Game Fish Bulletin No. 12, p. 1-59.

Overton, A.S., Margraf, F.J., Weedon, C.A., Pieper, L.H., and May, E.B., 2003, The prevalence of mycobacterial infections in striped bass in Chesapeake Bay: Fisheries Management and Ecology, v. 10, p. 301-308.

Rhodes, M.W., Kator, H., Kaattari, I., Gauthier, D., Vogelbein, W., and Ottinger, C. A., 2004, Isolation and characterization of mycobacteria from striped bass Morone saxatilis from Chesapeake Bay: Diseases of Aquatic Organisms, v. 61, p. 41-51.

\section{Epizootiology of mycobacteriosis in Chesapeake Bay striped bass (Morone saxatilis): Large-scale field survey.}

\author{
David T. Gauthier', Robert Latour', and Wolfgang \\ Vogelbein ${ }^{1}$
}

'Virginia Institute of Marine Science, The College of William and Mary, 1208 Greate Rd., Gloucester Point, VA 23062; email: gauthier@vims. edu.

Striped bass in Virginia and Maryland waters of Chesapeake Bay are experiencing an ongoing epizootic of mycobacteriosis. Visceral disease prevalence exceeding $50 \%$ has been reported in several locations by various authors, and skin lesion prevalence exceeding $30 \%$ has been observed. The high prevalence of skin lesions observed in Chesapeake Bay striped bass is unusual and has not, to our knowledge, been reported previously in wild fishes. It is alarming, as it may indicate that fish are progressing from chronic, covert infection to active, lethal disease. We have, however, observed putative healing lesions, so the prognosis of striped bass with skin lesions is unclear.

Various surveys continue to report high prevalence of mycobacterial disease in Chesapeake Bay striped bass; however, the overall picture regarding the scope and severity of the current epizootic remains unclear. The widespread nature of this epizootic, coupled with the highly migratory nature of striped bass, dictates that surveys with large spatial and temporal coverage must be employed to gain a better understanding of the disease on a population level. Further, surveys must be multi-year in nature in order to assess whether the epizootic is worsening, improving, or remaining constant over time.

Since 2003, we have been conducting a survey of mycobacteriosis in striped bass in Chesapeake Bay using the Chesapeake Bay Multispecies Monitoring and Assessment Program (ChesMMAP) platform (http://www.fisheries. vims.edu/chesmmap/). The ChesMMAP survey is intended to develop data on the distribution and feeding habits of fish species in Chesapeake Bay, and to apply these data to development of comprehensive multispecies management models. By virtue of its design and scale, this survey also provides an ideal sampling platform for studying disease in wild fish. Adult finfish are collected via balloon otter trawl five times per year over the entire Bay, ranging from the Bay mouth to the Susquehanna flats. Sampling is performed in 20-minute tows at 90 stations per cruise, with a stratified random design that covers all depths. Data collection on fish includes basic morphometrics (length, weight, eviscerated weight), otolithdetermined age, and gut content analysis. In addition, comprehensive environmental data are collected at each station. 
Mycobacterial disease status in striped bass is determined by histologic detection of granulomas, and severity index is calculated as granulomas $/ \mathrm{mm}^{2}$ of spleen.

From 2003-2005, disease status was determined for 1,645 fish. Ages ranged from 0 to 16 , with a male/female ratio of $\sim 3: 2$. In all 3 years of the survey, the first (late March) and last (late October) cruises of the year represented the majority of samples, but significant numbers of striped bass were also collected during summer (May-September) months.

Logistic regression analysis of 2003-2005 data indicates that risk of disease increases with age in both male and female fish, but per-year risk is significantly higher for male fish. Mycobacterial granulomas are observed in age-1 fish, indicating that sufficient risk factors are present within the Bay for expression of disease. The higher per-year disease risk of male fish may in part reflect their longer residence time in the Bay relative to females. This confounding influence of age and sex on prevalence must be taken into account when examining seasonal and regional apparent prevalence data. Regression models incorporating age, sex, cruise (season), region, and year indicate significant effects of all variables except year on disease status. This indicates that, taking other factors into account, the overall disease situation in the mainstem Bay was constant over the course of the study. Individual analyses of cruise and regional effects on disease status are complicated by several factors, and will be discussed in this presentation. Additionally, the fitting of various models to describe the observed apparent prevalence data will be described.

The relationship between mycobacterial disease status and fish condition has received considerable attention due to emaciation commonly observed in heavily diseased fish. The relationship between emaciation and disease in wild striped bass is a problem of causality, as equally plausible hypotheses can be presented where emaciation (e.g., due to lack of forage fish) leads to disease, and vice versa. The causal relationships involved here can only be determined by controlled laboratory studies. The association of disease with condition in the field, however, can provide useful information as to the overall health status of fish in varying stages of disease. Length/ eviscerated weight regression analysis of fish collected via the ChesMMAP survey indicated no significant association between disease category and weight-at-length (ANCOVA, $\mathrm{p}=0.073$ ). Some nonsignificant depression of weight-at-length was observed in severely diseased fish, and comparison of Clark's condition factor $\mathrm{K}$ (K=eviscerated weight/length $\left.{ }^{3 *} 10^{5}\right)$ between disease categories indicated significant reduction of condition in this group relative to no, minor, and moderate disease categories (ANOVA, $\mathrm{p}<0.001$ ). These findings indicate that in fish collected from the mainstem Bay, disease had minor, if any, effects on condition. It should be noted, however, that very few emaciated fish were collected via the ChesMMAP survey, unlike the larger numbers of these fish typically seen in tributaries.

\section{Mycobacteriosis in juvenile Atlantic menhaden.}

\author{
Andrew S. Kane ${ }^{1,2}$, Cynthia B. Stine ${ }^{2}$, Laura \\ Hungerford ${ }^{1,2}$, Mark Matsche ${ }^{3}$, Cindy Driscoll ${ }^{3}$, Larry \\ Pieper ${ }^{4}$, Kevin Rosemary ${ }^{4}$, John M. Jacobs ${ }^{4}$, and Ana \\ M. Baya ${ }^{2,6}$
}

'Department of Epidemiology and Preventive Medicine, University of Maryland School of Medicine, Baltimore, MD; email:akane@ umaryland.edu, lhungerf@epi.umaryland.edu. ${ }^{2}$ Aquatic Pathobiology Center, Virginia-Maryland Regional College of Veterinary Medicine, 8075 Greenmead Drive, College Park, MD 20742; email: cstin001@ umaryland.edu. ${ }^{3}$ Maryland Department of Natural Resources, Cooperative Oxford Laboratory, 904 South Morris Street, Oxford, MD 21654; email: mmatsche@dnr.state.md.us. ${ }^{4}$ Maryland Department of Natural Resources, Fisheries Service, 301 Marine Academy Drive, Stevensville, MD 21666; email: lpieper@dnr.state.md.us. ${ }^{5}$ NOAA/NOS/ Cooperative Oxford Laboratory, 904 South Morris Street, Oxford, MD 21654; email:john.jacobs@noaa.gov. ${ }^{6}$ Maryland Department of Agriculture, 8077 Greenmead Drive, College Park, MD 20742; email: ambaya@umd.edu.

Concerns have been raised by reports of a high prevalence of mycobacterial infection in striped bass, Morone saxatilis, in the Chesapeake Bay. However, the problem may be much more extensive with infection among multiple species of Chesapeake Bay fishes, including Atlantic menhaden, Brevoortia tyrannus. Atlantic menhaden is a keystone species in the Bay and other mid-Atlantic estuaries. They play an important ecological role as plankton feeders and are a critical prey species for birds and larger predatory fish including striped bass and bluefish. Menhaden also represent the largest commercial fishery in the Chesapeake Bay. They are commonly used as bait for "chumming," and are commercially harvested en masse (thousands of tons annually) for their protein. This protein is processed for use in animal feeds, as well as for their oil. Menhaden oil, which is rich in omega-3 fatty acids, is widely used in human and veterinary dietary supplements, and in cosmetics. The purpose of this study was to determine if juvenile Atlantic menhaden in the Chesapeake Bay are infected with mycobacteria. Juvenile menhaden were examined since they are the primary forage base for many Bay animals including striped bass.

An initial laboratory study was conducted with wildcaught juvenile Atlantic menhaden held under laboratory conditions. After 10 months, one fish was observed with a penetrating external ulcer, and Mycobacterium fortuitum complex and Mycobacterium spp. were recovered from the spleen and the ulcer of this fish, respectively. Subsequently, 20 additional fish were subsampled from this laboratory group to determine the prevalence of the infection. Full necropsies 
with histology were performed and samples were aseptically sampled from spleen (homogenized in BPBS), brain, liver, and kidney and plated on Middlebrook 7H10 agar supplemented with Bacto Middlebrook oleic acid, albumin, dextrose, and catalose. Plates were assessed for colony growth after 2-8 weeks and mycobacteria were identified to the genus level based on colony morphology, growth characteristics, and gas chromatographic fatty-acid methyl ester (FAME) analyses. All 20 fish in the subsample were found to be infected with mycobacteria. Three species of Mycobacterium were isolated from spleen tissues: M. marinum, M. fortuitum complex, and M. gordonae. Granulomas, characteristic of mycobacteriosis, were most prevalent in livers, but were also found in spleen, posterior kidney, and heart.

In a subsequent field study, Atlantic menhaden were collected by beach seine, cast net, or bank trap from the Choptank, Chicamacomico, Nanticoke, and Pocomoke Rivers of the Chesapeake Bay. Live fish were transported in oxygenated, insulated coolers to the laboratory for examination and microbiology. Liver tissues were aseptically sampled, homogenized in BPBS, and cultured, and mycobacteria were identified as described above. Prevalence of culture-positive fish was compared between river systems using Exact tests, with a Bonferroni correction when making multiple, pairwise comparisons

A low percentage $(<10 \%)$ of the Atlantic menhaden sampled had grossly visible, often perianal ulcers, penetrating through the skin and the underlying musculature. Histology results from a subsample of these specimens indicated that these lesions were consistent with ulcerative mycosis. Prevalence of mycobacterial infection differed significantly among wild-caught, juvenile Atlantic menhaden, ranging from 2-57\% by river system (Table 1). Atlantic menhaden from the Chicamacomico River had a higher prevalence $(\mathrm{p}<0.001)$ than menhaden sampled from the other river systems.

These studies support the conclusion that multiple species of mycobacteria can infect Atlantic menhaden. The relatively high prevalence of infection in wild-caught Atlantic menhaden is notable since this is one of the most abundant fish species in the Chesapeake Bay, and because this species represents an essential link in the food chain. The route of infection for Atlantic menhaden and other fishes remains unclear although horizontal and vertical transmission has been proposed. How-

Table 1. Prevalence data for mycobacteria in Atlantic menhaden from four Chesapeake Bay tributaries. Small letters indicate significant difference from other river systems at $p<0.01$ (Bonferroni corrected Fisher Exact probabilities).

\begin{tabular}{lcc}
\hline \multicolumn{1}{c}{ River (n) } & Prevalence (\%) & $\mathbf{9 5 \%} \mathbf{~ C l}$ \\
\hline Nanticoke (60) & $2^{\mathrm{a}}$ & $0.04-8.9$ \\
Choptank (134) & $10^{\mathrm{a}, \mathrm{b}}$ & $5.3-16.0$ \\
Pocomoke (46) & $21^{\mathrm{b}}$ & $11.0-36.4$ \\
Chicamacomico (47) & $57^{\mathrm{c}}$ & $42.2-71.7$ \\
\hline
\end{tabular}

ever, Atlantic menhaden commonly filter-feed on suspended sediments, and therefore water and sediment are also possible mechanisms for transfer to the host. Atlantic menhaden have previously been noted to be an excellent sentinel species for environmental exposure because of their sensitivity to a variety of environmental stressors. However, their ability to serve as a sentinel for the presence of bacterial pathogens is not clear. Demonstration of mycobacterial infection in juvenile Atlantic menhaden, both in the laboratory and in the wild, raises new questions about the epidemiology of mycobacteriosis in the Chesapeake Bay and the threat it poses to this critical keystone fish species.

Support for this study was provided by the Maryland Agriculture Experiment Station (MAES), the National Oceanic and Atmospheric Administration (NOAA), the Maryland Department of Health and Mental Hygiene, and the Centers for Disease Control and Prevention (CDC). 


\section{The influence of dietary intake on the progression and severity of mycobacteriosis in striped bass (Morone saxatilis).}

\author{
John M. Jacobs'1, Ana Baya², Martha Rhodes'1, \\ Renate Reimschuessel ${ }^{3}$, and Reginal M. Harrell ${ }^{4}$
}

${ }^{1}$ NOAA/NOS Cooperative Oxford Laboratory, Oxford, MD 21654. ${ }^{2}$ VAMD Regional College of Veterinary Medicine (VMRCVM), University of Maryland, College Park, MD 20742-3711. ${ }^{3}$ USFDA Center for Veterinary Medicine, Laurel, MD 20708. ${ }^{4}$ College of Agriculture and Natural Resources, Maryland Agricultural Experiment Station, University of Maryland, College Park, MD 20742-5551.

The relationship between the nutritional status of striped bass (Morone saxatilis) and the high prevalence of mycobacteriosis in Chesapeake Bay has been the source of much concern and speculation in recent years. Yet, basic information regarding the influence of nutritional state on the progression and severity of the disease in fish is lacking. Here we describe preliminary results from the first stage of a long-term challenge study designed to evaluate differential host response in experimentally infected fish fed optimal and sub-optimal rations.

Hatchery reared striped bass $(\mathrm{n}=512$, wt $=65+/-15 \mathrm{~g})$ were introduced to eight 300 -gallon recirculating systems over the course of 1 month to a final density of 64 fish per system. A previous health evaluation from this stock revealed a low-level (3/60) background infection with Mycobacterium marinum which was regarded as insignificant with the objectives of this study. One month prior to inoculation, fish were placed on one of two rations of Melick Aquafeed striped bass diet ( $4 \mathrm{~mm}$ ) and maintained throughout the course of the study at $21^{\circ} \mathrm{C}, 10 \mathrm{ppt}$ salinity, and $\mathrm{pH}$ of 8.2. A factorial design was used: replicate high ration control (HRC, $1 \%$ body weight/d), low ration control (LRC, $0.15 \%$ body weight/d), and high and low ration treatment (HRM and LRM). Mycobacterium marinum isolated previously from wild striped bass was passed through six 30-g fish and recovered from spleen homogenates. Experimental fish were inoculated intraperitoneally with $100 \mu \mathrm{L}$ of either a bacterial suspension resulting in a dose of 5-7 x $10^{4}$ colony forming units (CFU)/g body weight (Treatment) or BPBS (Control). A total of 12 fish per ration/ treatment were removed, euthanized, and aseptically sampled at inoculation and monthly thereafter. Blood samples were collected to determine white and red cell volume, and plasma protein levels. Liver and head kidney were cultured on Tryptic soy agar and broth. Spleen samples were frozen immediately at $-20^{\circ} \mathrm{C}$ and subsequently homogenized in BPBS and dilution plated on Middlebrook 7H10 agar for colony counts. Heart, liver, anterior and posterior kidney, spleen, lower intestine, gill, and reproductive tissues were preserved in $10 \% \mathrm{NBF}$ for histological preparation and whole carcasses were immediately frozen for subsequent chemical composition analysis. Proximate composition consisting of total moisture, neutral lipid, protein, and ash were conducted on homogenized abdominal tissue. Chemical composition of this region in juvenile striped bass has been shown in our lab to be highly correlated with total body composition, allowing for estimation of energetic components. All preliminary data analysis was conducted using general linear models in SAS v. 9.0 with plate count data log transformed.

Inoculation of M. marinum at 5-7 x $10^{4} \mathrm{CFU} / \mathrm{g}$ body weight resulted in a differential response among ration groups in clinical presentation, mortality, progression, and severity of granulomatous inflammation, bacterial density, and whole body energy. Grossly, by week 4 the visceral mass of both HRM fish was hardened, fused, and occasionally adhered to the body wall with nodular red foci apparent throughout the visceral fat, mesenteries, and body wall. Spleens were generally enlarged and friable as occasionally were head kidneys. By week 8, visceral adhesions and abundance of red foci were greatly reduced. Mortality among HRM fish totaled 3\% compared to $0 \%$ in controls. Lesions were more severe in LRM fish, which consistently had ascites, enlarged spleens, and more red foci throughout the abdomen. By 10 weeks, $87 \%$ of LRM fish died compared to $9 \%$ of low ration controls. These fish generally had a darkened appearance, were emaciated, and had pronounced ascites. All remaining low ration fish $(n=12)$ were sampled at this time interval and this portion of the study terminated.

Granulomatous inflammation in HRM fish followed a classical progression from loosely organized inflammatory cells and early granulomas to distinct, well-formed nodular lesions as described previously by Gauthier et al. (2003). Bacteria were visible at all progressive stages by ZiehlNeelsen staining. By 8 weeks, granulomas were generally well developed and rarely found outside spleen, anterior kidney, and mesenteric tissue. In contrast, an active, systemic inflammatory state generally persisted throughout the study period in LRM fish, characterized by a high prevalence of fused, poorly developed granulomas with enlarged, pale necrotic cores. The central pale eosinophilic necrotic material was surrounded by vacuolated macrophages and the cells comprising the fibrous capsules had a thicker, epitheliod morphology, versus the flat fibroblastic appearance of those in HRM fish. Acid-fast staining generally revealed a greater concentration of bacteria in LRM than HRM granulomas. Mortalities were generally characterized by systemic infection with intense peritonitis.

The intensity of the response in LRM fish and lack of resolution was associated with consistent splenic bacterial densities 2-3 logs $\left(\sim 10^{8}\right)(\mathrm{p}=0.001)$ greater than HRM fish, and a moderate decline in total body energy over the study period (-67 Kcal). In contrast, energy gain in HRM fish was slightly 
reduced, but not significantly different from high ration controls $(+306 \mathrm{Kcal}$ and $+330 \mathrm{Kcal}$ respectively, $\mathrm{p}=0.3375)$.

Red cell volume and plasma protein were reduced solely by low ration $(\mathrm{p}<0.01)$, with mycobacteriosis having little influence $(\mathrm{p}>0.05)$. Leukopenia was observed in inoculated fish receiving both diets, but was not noted in sham injected controls. Significant depression of white cell volume in HRM fish was apparent at 4 weeks $(p=0.02)$, but returned to baseline levels by 8 weeks $(p=0.77)$. In contrast, white cell volume continued to declined in LRM fish, becoming significantly different from that in low ration controls at 8 weeks $(\mathrm{p}=0.018)$.

Our data suggest that food quantity can impact the severity and progression of mycobacteriosis in experimentally infected striped bass. Low energy intake resulted in a severe, chronic, systemic infection characterized by high bacterial loading and gradual reduction in total body energy, which commonly progressed to mortality. In contrast, adequate energy intake resulted in classic granulamatous inflammation of reduced severity primarily associated with mesenteric and haematopoetic tissues, substantially reduced bacterial replication, and similar total body energy as found in un-inoculated controls. While the application of these data to wild striped bass is only theoretical, the potential impact of nutritional and other environmental stressors warrants further attention.

\section{Literature Cited}

Gauthier, D.T., Rhodes, M.W., Vogelbein, W.K., Kator, H., and Ottinger, C.A., 2003, Experimental mycobacteriosis in striped bass (Morone saxatilis): Diseases of Aquatic Organisms, v. 54, p. 105-117.

\section{Mycobacteriosis in Chesapeake Bay fishes: Perspectives and questions.}

\author{
Andrew S. Kane ${ }^{1,2}$, Laura Hungerford, ${ }^{1,2}$, Cynthia B. \\ Stine $^{2}$, Mark Matsche ${ }^{3}$, Cindy Driscoll ${ }^{3}$, John M. \\ Jacobs $^{5}$, and Ana M. Baya ${ }^{2,6}$
}

'Department of Epidemiology and Preventive Medicine, University of Maryland School of Medicine, Baltimore, MD; email:akane@ umaryland.edu; Ihungerf@epi.umaryland.edu. ${ }^{2}$ Aquatic Pathobiology Center, Virginia-Maryland Regional College of Veterinary Medicine, 8075 Greenmead Drive, College Park, MD 20742; email: cstin001@ umaryland.edu. ${ }^{3}$ Maryland Department of Natural Resources, Cooperative Oxford Laboratory, 904 South Morris Street, Oxford, MD 21654; email:mmatsche@dnr.state.md.us. ${ }^{4}$ Maryland Department of Natural Resources, Fisheries Service, 301 Marine Academy Drive, Stevensville, MD 21666; email: lpieper@dnr.state.md.us. ${ }^{5} \mathrm{NOAA} /$ NOS/Cooperative Oxford Laboratory, 904 South Morris Street, Oxford, MD 21654; email:john.jacobs@noaa.gov.6Maryland Department of Agriculture, 8077 Greenmead Drive, College Park, MD 20742; email: ambaya@umd.edu.

Environmental mycobacteria can be pathogenic to a variety of fishes and both wild and cultured species transmit mycobacteria to humans. As more and more data are amassed to better understand mycobacterosis in Chesapeake Bay fishes, new questions continue to emerge. The purpose of this abstract is to share notions that reveal the complexity of the relationship between environmental mycobacteria and piscine hosts in the Bay, and to offer ideas and questions to foster communication and collaboration within the management and research communities. Data from two studies will be presented to provide additional thoughts on water quality, species involvement, and semantics.

The first study was a controlled laboratory investigation of the effects of hypoxia on hybrid striped bass (Morone saxatilis x Morone chrysops) morbidity from mycobacteriosis. We identified a cultured population of adult hybrid striped bass that tested positive for mycobacteria but were subclinical, that is, not exhibiting lesions or grossly observable granulomas, and not emaciated. A subsample of this population $(n=26)$ was transported to the University of Maryland Aquatic Pathobiology Center, and eight fish were sacrificed upon arrival to determine the initial prevalence of mycobacterial infection. This initial prevalence was determined at $88 \%$ (95\% confidence interval (C.I.) 47.3-99.7\%). Fish were randomly distributed in 500-L experimental recirculating tanks ( $n=6 /$ tank). Water quality in each independent tank system was maintained through biofiltration. Dissolved oxygen (DO) was maintained at $7.0,4.5$, or $2.0 \mathrm{mg} / \mathrm{L}$ in each of the respective tanks using computer-controlled oxygen sensing and delivery systems. Fish were acclimated to experimental DO levels gradually, and 
maintained at those levels for 6 months. No deaths occurred throughout the holding period, except for one fish that jumped out of the $2.0-\mathrm{mg} / \mathrm{L}$ tank. At the end of the experiment, all fish were sacrificed and liver samples were cultured for mycobacteria. Only $2 / 6(33 \%, 95 \%$ C.I. $4.3 \%-77.7 \%), 2 / 6(33 \%, 95 \%$ C.I. $4.3 \%-77.7 \%)$ and $1 / 5(20 \%, 95 \%$ C.I. $0.5 \%-71.6 \%)$ fish remained culture-positive for mycobacteria from the 7.0, 4.5, and $2.0 \mathrm{mg} / \mathrm{L}$ DO regimes, respectively. Although the number of mycobacterial CFUs were low from "culture-positive" fish, the lower prevalence at the end of the experiment $(\mathrm{p}=0.01$, pooled prevalence $5 / 17,29 \%, 95 \%$ C.I. $10.3 \%-56.0 \%$ ) suggests that fish may be able to recover from an "infected" state to a healthy, "uninfected" state. Further, hypoxia alone, in the absence of any other water-quality stressors or confounding variables, does not appear to potentiate mycobacterial disease progression in hybrid striped bass.

The second study investigated the presence of mycobacteria in wild-captured fish collected using beach seines, cast nets, or bank traps from the Chicamacomico and Pocomoke Rivers of the Chesapeake Bay. Fish were transported live, immediately following capture, to the laboratory for necropsy. No externally visible lesions were present on any fish. Spleen tissue was aseptically sampled, homogenized in BPBS, and plated on Middlebrook 7H10 agar supplemented with Bacto Middlebrook OADC for mycobacterial growth. Mycobacteria were recovered from seven species of fish (Table 1). These data indicate that mycobacteria can infect multiple Chesapeake Bay fish species, in addition to striped bass and Atlantic menhaden.

Interpretation of results from these two studies emphasizes the importance of terminology in describing diagnostic test results and true infection or disease status. Simple recovery of very low CFUs (i.e., $<10^{2} / \mathrm{g}$ ) of mycobacteria from an animal's spleen suggests that the animal is indeed infected. However, low CFU data alone are likely insufficient to determine if an active infection is in progress. Infection represents a continuum from invasion, to phagocytosis, to bacterial multiplication in a tissue, to tissue injury and granuloma formation, and potentially, to overt disease (i.e., altered behav- ior, inappetence, petechial hemorrhage, fibrosis, adhesions, emaciation, severe granulomas, co-infection, etc.). Fish can also be variously classified as subclinical carriers or clinically diseased along this spectrum. These semantics are key because many reports of the prevalence of mycobacteria in fish populations do not differentiate between "carrier" status and "disease" status. This distinction is important since the impacts of infection and frank disease differ both for individual fish and for populations. Further, data from several studies in the literature (including the hypoxia study, above) indicate that fish can recover from clinical disease and/or can clear themselves of mycobacterial infections.

The notion of recovery is key because it indicates that, in the absence of continued infection pressure or stressors, fish may be able to heal themselves. Since it is impossible to eradicate mycobacteria from the Bay environment, it seems reasonable that management efforts need to focus on decreasing stressors that either foster mycobacterial infection in healthy fish, or lead to disease progression in subclinically infected (carrier) fish. Further, management should strive to reduce the constituents within the environmental media that foster growth of mycobacteria. Figure 1 provides an initial schematic representation of mycobacterial infection, disease progression, recovery, and the role of environmental stressors.

This conceptual framework provides a means for considering additional questions about the epidemiology of mycobacterial infections among fish. Are mycobacterial infections in Chesapeake Bay biota an emerging issue or have piscine infections gone mostly unnoticed due to the relatively challenging nature of mycobacterial culture, isolation, and identification? What is the biological relevance of prevalence based solely on detection of mycobacteria in the absence of clinical disease state? What factors may affect higher prevalence data in different river systems? Is the environmental state of the Bay such that we are poised to see large numbers of different organisms affected with disease in the presence of other, predisposing stress factors? Data presented at this workshop may help refocus attention and resources on the anthropogenically accelerated eutrophication of one of our most valuable natural

Table 1. Prevalence of isolation of mycobacteria from fishes from two Chesapeake Bay tributaries.

\begin{tabular}{lcc}
\hline \multicolumn{1}{c}{ Species (n) } & Prevalence & $\mathbf{9 5 \%} \mathbf{~ C l ~}$ \\
\hline Blueback herring, Alosa aestivalis (17) & $12 \%$ & $1.5-36.4$ \\
Winter flounder, Pleuronectes americanus (26) & $12 \%$ & $2.5-30.2$ \\
Striped killifish, Fundulus majalis (1) & $100 \%$ & $2.5-100.0$ \\
Mummichog, Fundulus heteroclitus (3) & $33 \%$ & $0.8-90.6$ \\
Largemouth bass, Micropterus salmoides (1) & $100 \%$ & $2.5-100.0$ \\
Weakfish, Cynoscion regalis (2) & $50 \%$ & $1.3-98.7$ \\
Spot, Leiostomus xanthurus (27) & $7 \%$ & $0.9-24.3$ \\
White perch, Morone americana (87) & $20 \%$ & $11.8-29.4$ \\
\hline
\end{tabular}




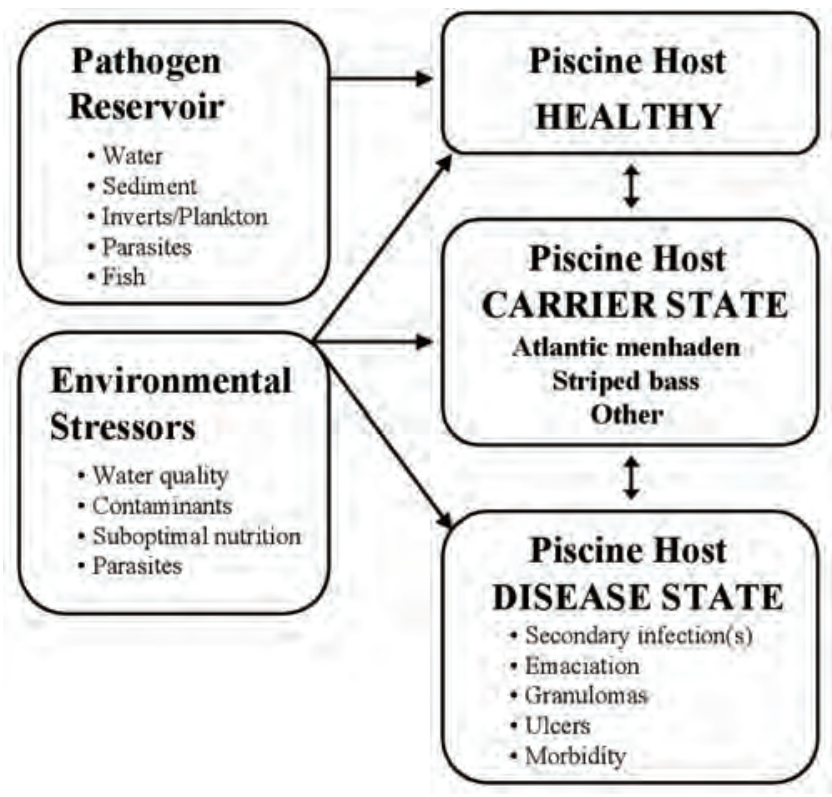

Figure 1. Schematic diagram showing mycobacterial disease progression and recovery in fish. The effects of environmental stress are shown to affect the state of the host. However, environmental conditions can also affect the density of mycobacteria in the reservoir.

resources, and discussion of these enriched estuarine waters as an environmental reservoir for mycobacteria.

Support for portions of these studies was provided by the Maryland Agriculture Experiment Station (MAES), the National Oceanic and Atmospheric Administration (NOAA), the Maryland Department of Health and Mental Hygiene, and the Centers for Disease Control and Prevention (CDC).

\section{Initial investigation of the overall health and presence of mycobacteriosis in Roanoke River, NC, striped bass (Morone saxatilis).}

\author{
Anthony S. Overton', John M. Jacobs², John W. \\ Stiller ${ }^{3}$, and Eric B. May ${ }^{4}$ \\ 'East Carolina University, Thomas Harriot College of Arts and Science, \\ Department of Biology, Howell Science Complex, Greenville, NC 27858; \\ email:OvertonA@ecu.edu. ${ }^{2}$ NOAA/NOS Cooperative 0xford Lab, 904 \\ South Morris Street, Oxford, MD 21654. ${ }^{3}$ East Carolina University, \\ Thomas Harriot College of Arts and Science, Department of Biology, \\ Howell Science Complex, Greenville, NC 27858. ${ }^{4}$ NOAA Living Marine \\ Resources Cooperative Science Center, Department of Natural \\ Sciences, University of Maryland Eastern Shore, Princess Anne, MD \\ 21653.
}

The prevalence of mycobacteriosis in Chesapeake Bay has received considerable attention. However, little information exists for striped bass from other regions of their Atlantic Coast range. To address this concern, we examined adult striped bass at Weldon and Jamesville on the Roanoke River, NC, during April of 2003.

Sixty striped bass were collected from the Roanoke River and ranged in size from $260 \mathrm{~mm}$ to $790 \mathrm{~mm}$ (total length). Weight, length, condition factor, relative mesenteric body fat, and gross observation of external and visceral lesions and parasite burden were conducted in the field. Sections of liver, spleen, and head kidney were both preserved in $10 \% \mathrm{NBF}$ and frozen at $-20{ }^{\circ} \mathrm{C}$ for routine paraffin histology and molecular detection and identification of Mycobacterium spp. Genetic probing of tissues was accomplished with Mycobacterium-specific PCR amplification of the 16s rRNA gene with amplification products sequenced and compared against previously reported Mycobacterium species sequences.

Sequences of the small subunit ribosomal RNA gene (16S rDNA) were obtained from all Mycobacterium species available, by database searches and from unpublished sequences provided by colleagues. We also retrieved sequences from a broad range of bacteria that might be present on striped bass, or in their habitats. Sequences were aligned using the computer program CLUSTAL W (Thompson et al., 1994) and adjusted by eye. We examined alignments for regions of sequence that were conserved in Mycobacterium (the same sequence in all species within the genus), but different in other bacteria that might be present in mixed samples. We also assayed primer sequences designed previously by other researchers to amplify complete mycobacterial 16S rDNA sequences from environmental samples (Rhodes et al., 2001). Total sequence diversity found among Mycobacterium, 
along with the sequence similarity present in closely related bacteria, precluded the design of absolutely specific primers. In total, six primers were constructed and tested.

Males made up $68 \%$ of the sample and $32 \%$ were females. Low-level infestations of intestinal parasites were present in nearly $80 \%$ of the fish. All of the striped bass examined had visible fat deposits in the viscera with $95 \%$ having some traces of visceral fat or moderate accumulation of fat. Granulomas were present in $83 \%$ of the fish with the vast majority being of verminous origin. Acid-fast bacteria were detected within at least one organ in $18 \%$ of the striped bass with the highest percentage $(8.3 \%)$ visualized in the spleen, followed by mesenteric tissues. Low numbers of granulomas containing acid-fast bacteria were detected in the heart, liver, and head kidney. Acid-fast bacteria were detected in multiple organs in only $5 \%$ of the fish examined. The observed granulomas containing acid-fast bacteria are consistent with mycobacteriosis but no Mycobacterium sp. were detected by PCR amplification. All sequences recovered were from members of the bacterial order Actinomycetales, family Corynebacterineae, to which the genus Mycobacterium belongs. The two most common sequences were from Corynebacterium sundsvallense and $C$. thomssenii, two closely related species first described in 1999. C. sundsvallense has been isolated only from human clinical samples, while $C$. thomssenii has also been isolated from an air sample. The discrepancy between the visual observation of granulomas containing acid-fast bacteria and PCR results must be addressed in future efforts. It is clear that other factors including contamination, low levels of Mycobacterium in the fish samples, a higher prevalence of Corynebacteria than Mycobacterium in the tissues, or differences in the DNA extraction efficiency for the species involved may have influenced our results. The observed granulomas containing acid-fast bacteria are consistent with mycobacteriosis. It should also be noted that Corynebacterium are not acid fast and have different morphology than Mycobacterium. We conclude that striped bass in the Roanoke River have been exposed to acid-fast bacteria, but presumptive mycobacteriosis in the population has not been confirmed by PCR or culture.

\section{Literature Cited}

Rhodes, M.W., Kator, Howard, Kotob, Shaban, van Berkum, Peter, Kaattari, Ilsa, Vogelbein, Wolfgang, Floyd, M.M., Butler, W.R., Quinn, F.D., Ottinger, Christopher, and Shotts, Emmett, 2001, A unique mycobacterium species isolated from an epizootic of striped bass (Morone saxatilis): Emerging Infectious Diseases, Dispatches, v. 7, p. 896-899.

Thompson, J.D., Higgins, D.G., and Gibson, T.J., 1994, Clustal W improving the sensitivity of progressive multiple sequence alignment through sequence weighting, positionspecific gap penalties and weight matrix choice: Nucleic Acids Research, v. 22, p. 4673-4680.

\section{Mycobacterial infections in striped bass (Morone saxatilis) from Delaware Bay.}

Christopher A. Ottinger ${ }^{1}$, J. Jed Brown², Christine L. Densmore ${ }^{1}$, Cliff E. Starliper ${ }^{1}$, Vicki S. Blazer ${ }^{1}$, Holly S. Weyers ${ }^{3}$, Katherine A. Beauchamp ${ }^{1}$, Martha W. Rhodes $^{4}$, Howard Kator ${ }^{4}$, David T. Gauthier ${ }^{4}$, and Wolfgang K. Vogelbein ${ }^{4}$

'U.S. Geological Survey, Leetown Science Center, National Fish Health Research Laboratory, 11649 Leetown Road, Kearneysville, WV 25430; email:cottinger@usgs.gov,cdensmore@usgs.gov,cstarliper@ usgs.gov,vblazer@usgs.gov, kbeauchamp@usgs.gov. ${ }^{2}$ U.S. Fish and Wildlife Service, Delaware River Fisheries Coordinator's Office, 2610 Whitehall Neck Road, Smyrna, DE 19977; email:Jed_Brown@fws. gov. ${ }^{3}$ U.S. Geological Survey, Water Resources Discipline, Dover Field Office, 1289 McD Drive, Dover, DE 19901; email: hsweyers@usgs.gov. ${ }^{4}$ Department of Environmental and Aquatic Animal Health, Virginia Institute of Marine Science, College of William and Mary, P.O. Box 1346, Gloucester Point, VA 23062; email: martha@vims.edu,kator@ vims.edu,gauthier@vims.edu,wolf@vims.edu.

Much of what is known of mycobacteriosis in wild striped bass from the mid-Atlantic region of the United States is based on our observations from Chesapeake Bay and its tributaries, where high infection prevalence and lesioned fish are frequently observed. Comparatively, the occurrence and severity of mycobacteriosis in striped bass from watersheds adjacent to Chesapeake Bay are relatively unknown. This study represents the first report on mycobacterial infection in striped bass harvested from two sites in Delaware Bay.

Eighty striped bass (Morone saxatilis) were obtained from Delaware Bay using commercial gill-nets located adjacent to Woodland Beach $\left(39.333^{\circ} \mathrm{N}, 75.475^{\circ} \mathrm{W} ; \mathrm{n}=70\right)$ and Bowers Beach $\left(39.058^{\circ} \mathrm{N}, 75.397^{\circ} \mathrm{W} ; \mathrm{n}=10\right)$ in December of 2003. Bowers Beach and Woodland Beach samples were obtained over an 8-day period on one and three sample dates, respectively. Nets were fished for approximately $24 \mathrm{~h}$, and live striped bass were removed and transported to shore in a water tank fed by pumped surface water. Fish were euthanized with a lethal dose of an anesthetic agent, packed in ice, and transported to the USGS National Fish Health Laboratory (Leetown, WV) for further processing. At necropsy for each specimen, fish were examined for gross external and internal lesions as well as the presence of parasites; total lengths and eviscerated weights were determined to calculate condition factor $(\mathrm{K})$; and tissue samples were collected. Portions of spleens were aseptically harvested for bacterial culture, and tissue specimens were collected in Z-fix preservative for histological examination. Tissue specimens for histological 
and bacteriological analyses were processed routinely using methods previously described and utilized for similar studies with Chesapeake Bay striped bass populations. Spleen, liver, kidney, and gonad were evaluated histologically for lesions, including presence and severity of granulomatous inflammation; presence of acid-fast bacteria associated with splenic, hepatic, and renal granulomas; and presence of parasites. Homogenates of aseptically harvested spleen tissue were serially diluted and plated onto Middlebrook and Brain Heart Infusion agars for bacterial isolation and enumeration. Recovered acid-fast and non-acid-fast bacteria were further characterized biochemically. Statistical analyses of results were performed using analysis of variance (size, condition factor), Pearson chi-square and two-tailed Fisher exact test (bacterial and parasite infection intensities, granuloma occurrence). All statistical analyses were performed using SYSTAT 11 (SYSTAT Software, Inc., Point Richmond, CA). Statistical significance was designated as $\mathrm{p}<0.05$.

No differences were noted based on size or condition of the fish. The size distribution of the striped bass was relatively homogeneous with mean total lengths of about $600 \mathrm{~mm}$ in all samples. Mean condition factors exceeded 0.95 in all samples and were not significantly different among the samples.

Pooled condition factors for mycobacterial infected $(n=14)$ and noninfected $(n=66)$ striped bass were also not significantly different. With the exception of rectal nodules associated with acanthocephalan infections, no gross abnormalities were observed either externally or internally among these striped bass. The percentage of fish with coelomic nematode infections ranged from 26.6 - 69.2\% and did not differ significantly among sample collections. The percentage of striped bass with rectal acanthocephalan infections was significantly different among samples, such that collections made at both sites on 12/09/03 and 12/10/03 (61.5 - 70.0\%) were significantly higher than the Woodland Beach sample collected on 12/17/03 (21.4\%) but were not significantly different from each other. No significant differences in granuloma prevalence were observed among samples. Prevalence of acid-fast bacilli observed in association with splenic granulomas was low overall $(6.25 \%, \mathrm{n}=80)$, and acid-fast bacilli were not observed in association with any liver or kidney granulomas. The occurrence of encysted helminthes in spleens was a common observation, but parasites were very seldom noted in association with granulomas in the liver, kidney, or gonad. Significant differences in mycobacterial infection prevalence (as determined by the combination of bacterial culture and histopathology) were observed among samples, with those obtained at Woodland Beach on 12/10/03 (53.8\%, $\mathrm{n}=13)$ and $12 / 17 / 03(7.1 \%, \mathrm{n}=42)$ exhibiting the most striking differences. Mycobacterial infection intensities ranged from about $10^{2}$ to $10^{7} \mathrm{CFU} \mathrm{g}{ }^{-1}$ spleen. Ten acid-fast isolates were obtained from the Delaware Bay striped bass in all, and only one presumptive Mycobacterium sp. was isolated from each positive sample. Seven of the ten acid-fast isolates were characterized by biochemical phenotyping. Only one of the seven Mycobacterium isolates, identified as $M$. chelonae, exactly fit existing species descriptions. Non-acid-fast bacterial infection prevalence was also significantly different among the samples. Infection intensities ranged from $10^{3}$ to $10^{5} \mathrm{CFU} \mathrm{g}{ }^{-1}$ spleen. Lactococcus lactis ssp. lactis, and Pseudomonas fluorescens were the most frequently identified non-acid-fast species.

Mycobacterial infection prevalences observed in the Delaware Bay samples were substantially lower than that reported for striped bass in Chesapeake Bay. In general, the infection intensities in these Delaware Bay striped bass were also lower than those previously reported for mycobacteria culture-positive striped bass of similar size from Chesapeake Bay. Although overall condition of these striped bass among the four Delaware Bay samples was rather homogeneous, differences in mycobacterial infection prevalence, non-acid-fast bacterial infection prevalence, and acanthocephalan infection prevalence were apparent. Differences in microbial exposures, diet, contact with environmental stressors, or genetic background might explain the intersample variation in bacterial and parasitic infections observed among these fish. 


\section{Tag-recapture data from Chesapeake Bay striped bass indicate that natural mortality has increased.}

\author{
Desmond M. Kahn' and Victor Crecco²
}

'Delaware Division of Fish and Wildlife, P.0. Box 330, Little Creek, DE 19961; email: desmond.kahn@state.de.us; 302-739-4782 x19. ${ }^{2}$ Connecticut Division of Marine Fisheries, 333 Ferry Rd., Old Lyme, CT 06371; email: vic.crecco@po.state.ct.us; 860-434-6043.

Coast-wide tagging studies of striped bass have been conducted annually since 1987 to determine trends in fishing mortality (F) rates. Annual tag-recovery studies have been performed during spring in all producer areas (Chesapeake Bay, Hudson River, and Delaware River), as well as during spring and fall along the coast from North Carolina to Massachusetts. Atlantic Coast striped bass are highly migratory and larger $(>75 \mathrm{~cm} \mathrm{TL})$ stripers tagged initially in Chesapeake Bay are often recovered coast-wide from North Carolina to New England. The U.S. Fish and Wildlife Service's Annapolis Office has managed the tagging database and the Atlantic States Marine Fisheries Commission's Striped Bass Tagging Subcommittee has analyzed the data with a standard protocol.

Until recently, stock assessment methods such as Virtual Population Analysis (VPA) and tag-based models on striped bass have assumed that natural mortality of all sizes of striped bass are constant $(\mathrm{M}=0.15)$ over time. Under the constant $\mathrm{M}$ assumption, fishing mortality (F) estimates on striped bass can easily be derived by subtracting a constant $\mathrm{M}$ of 0.15 from the total mortality $(\mathrm{Z})$ rate. Although the constant $\mathrm{M}$ assumption has been used almost universally in most finfish stock assessments, there is a growing body of evidence in the fisheries literature that natural mortality among most finfishes may vary systematically over time due to changes in biotic and abiotic factors, and may be also under the influence of density-dependent factors. Determining whether or not $\mathrm{M}$ is constant for striped bass is particularly important to test the hypothesis that the recent mycobacteriosis outbreak on striped bass in Chesapeake Bay after 1995 may have been linked to a recent rise in $\mathrm{M}$.

In this study, we used the Baranov catch equation to estimate fishing (F) and natural mortality (M) independently for Chesapeake Bay stripers based on a time series (19872004) of tag-recovery data. In the first step of this approach, tag-recovery data were used to estimate a time series of annual harvest (u) and total mortality (Z) rates for 18 in.+ and 28 in.+ striped bass from the Bay and elsewhere. We then substituted the annual $u$ and $\mathrm{Z}$ estimates into the Baranov catch equation from which a time series of fishing $(F)$ mortality rates was derived. Given total (Z) and fishing mortality (F), natural mortality (M) estimates were then derived from 1987 to 2004 by subtracting $\mathrm{F}$ from $\mathrm{Z}$. This catch equation approach has allowed us to specifically test the hypotheses that $\mathrm{M}$ is constant at 0.15 for striped bass in Chesapeake Bay and elsewhere from 1987 to 2004. Moreover, the time series of M estimates from Chesapeake Bay stripers allowed us to test the hypotheses of a causal linkage between the documented mycobacteria outbreak on Chesapeake Bay stripers after 1995 and a rise in striped bass mortality.

Our results indicated that tag-based total mortality (Z) estimates on smaller (> 18 in.) in upper Chesapeake Bay have risen steadily since 1995, but fishing mortality $(\mathrm{F})$ from the catch equation approach remained steady at about 0.25 from 1995 to 1999 , then dropped steadily thereafter from 2000 to 2004. As a result, natural mortality (M) estimates on smaller stripers from the upper Chesapeake Bay rose from 0.13 in 1995 to peak levels $(M=0.47)$ in 2001 . The M estimates after 2001 have dropped slightly (M range: 0.38-0.43) but were much higher in magnitude than $\mathrm{M}$ estimates prior to 1997. Moreover, M estimates on smaller (18 in.+) striped bass from the Rappahanock River, Virginia, also rose even more abruptly, from about 0.12 in 1993 to peak levels of 0.73 in 1999. Unlike the trend in M for upper Bay stripers, the M estimates on Virginia stripers fell abruptly after 2001 to pre-1997 levels. The trends in $\mathrm{M}$ for Maryland and Virginia stripers exhibited a significant positive correlation. The timing of the increase in $\mathrm{M}$ throughout Chesapeake Bay coincided with the reported outbreak of mycobacteriosis, thereby supporting the hypothesis that mycobacteriosis caused enhanced natural mortality of resident striped bass in Chesapeake Bay.

Although $\mathrm{M}$ estimates on resident striped bass in Chesapeake Bay fell after 2001, natural mortality levels for Maryland migratory striped bass (28 in.+) increased from 0.10 in 1997 to 0.39 in 2004. This systematic increase in $\mathrm{M}$ is also in accord with the hypothesis that links the mycobacteriosis outbreak with a rise in $\mathrm{M}$ for migratory striped bass from upper Chesapeake Bay. The Virginia results for 28 in.+ fish, however, do not show a consistent increase in natural mortality (M) from 1997 to 2004. To pursue the mycobacteriosis hypothesis, one possible explanation for an increase and then a decline in natural mortality levels, which occurred independently in both Maryland and Virginia, is that more susceptible striped bass died due to the disease whereas the remaining fish may be more resistant.

Finally, we used the Striped Bass Harvest Control Model (HCM) to determine whether or not the recent rise in resident striped bass recreational catches (harvested and released) and landings (harvested) during fall (Sept.-Oct.) from Maryland was consistent with a rise in natural mortality. The observed recreational catch and harvest data from 1984 to 2004 were based on the MRFSS survey. The observed fall recreational catches of striped bass in Maryland have remained persistently high from 1997 to 2004, but the fall harvest levels have fallen steadily from peak levels in 1996. We used the HCM to simulate the recreational catches and landings data from 1984 to 2004 under the assumption of a rise in natural mortality (M) 
of resident striped bass. The model output (simulated catches and harvest) in the HCM was expressed as year (1984-2004) and age (ages 1-9) effects. Input parameters in the HCM include growth parameters in length $(\mathrm{mm})$ and weight $(\mathrm{kg})$ by age, percentage maturity by age, natural mortality $(\mathrm{M})$ by year according to our $\mathrm{M}$ estimates from tagging and recruitment (age 0) by year-class based on the Maryland juvenile index. We assumed that the simulated recreational catches were composed of ages $1+$ stripers, whereas the landings were composed of ages $3+$ striped bass using a partial recruitment vector that was consistent with the current 18.0-in. minimum size limit. The HCM output would support the hypothesis of a rise in $M$ if the trends in simulated fall recreational catches and harvest from 1995 to 2004 were similar to the trends in observed fall recreational data. Results from the HCM indicated that the simulated fall catches and landings from 1995 to 2004 under a simulated rise in $\mathrm{M}$ were very similar to the trends in the observed fall recreational catches and harvest. These findings suggest that a rise in natural mortality since 1996 has apparently reduced the number of legal-size (18 in.+) stripers in the recreational harvest after 1997. However, the attrition effects of enhanced natural mortality are less likely to be manifested on younger (ages 1-3) stripers, thereby leading to more stable fall catches of ages 1+ stripers in Maryland from 1996 to 2004. These findings are consistent with our stated hypothesis that $\mathrm{M}$ on resident striped bass has risen systematically since 1995 . The model results did indicate, however, that the HCM could reproduce a similar trend in fall recreational catches and harvest under a constant $\mathrm{M}$ if either striped bass somatic growth declined systematically after 1995 , or if striped bass migration rates from the Bay to the Coast accelerated after 1995.

\section{Epizootic mycobacteriosis in Chesapeake Bay striped bass: What is the fate of infected fish?}

\author{
Wolfgang K. Vogelbein'1, John M. Hoenig², and David \\ T. Gauthier ${ }^{1}$
}

'Department of Environmental and Aquatic Animal Health and ${ }^{2}$ Department of Fisheries Science, Virginia Institute of Marine Science, The College of William and Mary, 1208 Greate Rd., Gloucester Point, VA 23062; email:wolf@vims.edu.

Striped bass (Morone saxatilis) in Chesapeake Bay, USA, are currently experiencing an epizootic of mycobacteriosis. Visceral disease prevalence in resident fish exceeds $50 \%$ and prevalence of skin ulcers can exceed $30 \%$ in some areas. Two primary hypotheses regarding emergence of this chronic bacterial disease propose that anthropogenic stressors constitute important underlying modulating factors. The first suggests that elevated nutrient inputs to the Bay and the associated eutrophication results in loss of summer thermal refugia for striped bass, forcing the fish into sub-optimal and stressful habitat during the warm summer months. The second hypothesis proposes alterations in trophic structure and starvation as a result of over-harvesting of key prey species such as Atlantic menhaden (Brevoortia tyrannus) and reductions in the food forage base. Ongoing striped bass tagging programs in Maryland and Virginia indicate a significant increase in non-fishing (natural) mortality in recent years. The contribution of mycobacteriosis to this increased mortality and which, if any, environmental factors modulate disease expression in Chesapeake Bay remain unclear. The high disease prevalence and concurrent increase in natural mortality of striped bass in recent years are of great concern to environmental scientists, fisheries managers, and anglers. A critical question regarding striped bass mycobacteriosis pertains to potential adverse impacts of the disease at the population level. Does the disease cause mortality in striped bass and will it have a long-term detrimental effect on the Atlantic Coastal migratory stock?

During 2005 we initiated field studies to determine whether mycobacteriosis is a cause of significant mortality in striped bass. The objectives of this study were to determine the rate of progression/regression of dermal disease by holding striped bass under field conditions (caging studies) to determine the relative mortality of fish with and without visible skin lesions, and to develop and apply a statistical model to estimate relative survival in fish with and without visceral disease as predicted by the presence of skin lesions (tagging studies). To accomplish this we made use of an existing annual striped bass tagging program at Virginia Institute of Marine 
Science and initiated short-term field caging studies in the Rappahannock River, Virginia.

During fall 2005 we photographed (to document fish health status), tagged, and released a total of 1,811 striped bass belonging to two groups, fish that exhibited skin lesions characteristic of mycobacteriosis and fish without them. The rationale for this approach was that if the disease causes mortality, then tag returns from the group of fish exhibiting disease signs should be lower than returns from the group without signs of the disease. This study is ongoing and another large group of fish with and without external clinical signs will be tagged during 2006. The fraction of tags returned from each group will then be used to estimate relative survival (i.e., impact of the disease). We have established and widely publicized a tag return reward program in collaboration with the Virginia Marine Resources Commission (VMRC) that will motivate commercial and recreational anglers to return whole tagged fish to us on ice. We offer a \$20 reward for the return of a whole fish tagged with a special fluorescent green internal anchor tag and \$5 for return of the tag only. Additionally, VMRC has issued an exemption in effect from 2005 - 2008 for all striped bass with the green streamer tag. Tagged fish will not count against daily creel limits or tag quotas and fish size and seasonal restrictions will not apply to these fish. Because we photo-document health status of all fish prior to tagging and release, this program should also provide important information on skin lesion progression or regression/healing over the course of the study. As of April 2006, we have had $\sim 120$ tag returns ( $6.6 \%$ tag return rate), many of which were returned to us as whole fish. Most of these returns were shortterm recaptures by commercial pound net fishermen working in the mouth of the Rappahannock River.

We have held fish with and without skin lesions in two large net pens deployed in the upper Rappahannock River (near Tappahannock, VA) during fall 2005. This study was conducted in order to observe short-term temporal aspects of disease prevalence, severity, survival rates, and progression/ healing. Weather conditions were unusual during this time period, with water temperatures remaining high $\left(>20^{\circ} \mathrm{C}\right)$ very late into the season, followed by a rapid dropoff of temperatures to $<10{ }^{\circ} \mathrm{C}$. The optimal temperature range for striped bass lies between these two values; therefore, we were not able to keep striped bass in the pen enclosures for the amount of time that we anticipated. We were, however, able to maintain some fish in the pen for up to $10 \mathrm{wk}$. Histological analysis of these fish is in progress. Changes in skin lesion appearance were subtle or absent in penned fish over the course of the study, suggesting that these changes occur over relatively long periods of time. We plan to repeat this study during fall 2006. As striped bass are stressed at very low salinities such as those observed in the upper reaches where we deployed the net pens in 2005, we plan to move them to the mouth of the Rappahannock River in 2006 to take advantage of the higher salinity regime.

Estimation of relative mortality between diseased/nondiseased animals via tag-recapture studies requires non-lethal diagnostic methods for determination of disease/exposure state. A serologic test of disease status would be ideal, as a small sample of blood could be collected prior to fish tagging and release. However, such a non-lethal diagnostic is not yet available for mycobacteriosis in striped bass. We have therefore focused efforts on better characterization and detection of what we believe to be the very earliest and most subtle skin pathologies associated with mycobacteriosis in the striped bass. Based on extensive histological verification, we consider these lesions to be pathognomonic (specific) for the disease and feel that their prevalence has been significantly underestimated in prior studies. We believe this to be one of the reasons for the large disparity between skin (30\%) and visceral (50-70\%) disease prevalence. Better tracking of these early skin lesions will provide us with higher concordance between the dermal and visceral disease states and will allow use of skin pathology as an indicator of overall disease state in lieu of a non-lethal serologic test. This work was funded in part by the Virginia Marine Resources Commission and Virginia Sea Grant Program. 


\title{
Perspective of Resource Managers
}

\author{
Facilitator \\ Frank Panek - U.S. Geological Survey, Leetown Science Center
}

Resource managers were asked to provide an opening statement in which they were to summarize their respective agency's perspective on mycobacteriosis in striped bass and to offer comments on issues of concern to them as a resource management agency within the Chesapeake Bay system. These initial agency comments were to provide a forum for questions and discussions by the workshop participants on how the research community could help address the informational needs of the resource managers. To capture these discussions for the record, staff members from the Chesapeake Research Consortium served as recorders. The following summaries reflect the initial comments made by the managers and the questions and discussions that followed.

\section{Steve Giordano NOAA, NMFS, Chesapeake Bay Office}

Statement: In the past, NOAA managed fisheries based on individual species and small spatial scale. Ecosystem-based fisheries management has replaced the single-species approach with multiple fish species managed as a group. This is an adaptive ecosystem approach to management that includes integrated fisheries assessments, product syntheses, modeling, and analysis. NOAA is responsible for developing the new Ecosystem Based Fisheries Management Plan for Chesapeake Bay and provides Federal support for State management authorities through the NOAA Chesapeake Bay Office (NCBO). The NCBO coordinates and facilitates NOAA efforts in Chesapeake Bay and acts as a liaison to NOAA headquarters and other offices nationwide. In general, information most likely to meet NOAA's needs would be based on data that can support the adaptive ecosystem management process. The National Marine Fisheries Service needs information on the current epizootic of mycobacteriosis in striped bass of Chesapeake Bay and elsewhere to evaluate the possible implications for the management of the striped bass stock in the Economic Exclusion Zone (EEZ).

\section{Comments, Questions, and Answers by Workshop Participants:}

Comment - Striped bass are protected and it's not good to sample the spawning stock.

Question - Is there going to be any enforcement in the EEZ? - There will be some limits and regulations on size, age, etc. - how will they be enforced?

Response - The public comment period for opening the EEZ to striped bass fishing continues to May 24, 2006. This is a good opportunity for asking questions and expressing concerns on the opening of the EEZ. When the EEZ is open, the landing laws of individual states (bag limits, size, etc.) will be enforced at the ports. States will have the regulatory role - not the Federal government.

\section{Nancy Butowski Maryland Department of Natural Resources (MD DNR)}

Statement: The MD DNR Fisheries Service is most interested in answers to the following questions: How many fish are dying from this disease? What is the nutritional status of striped bass? Are environmental factors such as excess nutrients and pollution impacting the disease? What are the human health impacts and what steps should be taken to keep humans safe? What are the important research questions that MD DNR should promote and fund? What message do we need to get across to the public about the presence of disease and how it affects the Chesapeake Bay?

The information on how many striped bass are dying from the disease will improve our ability to calculate the natural mortality rate for stock assessments on striped bass. The nutritional status of striped bass is in question regarding whether the disease leads to poor body condition or whether poor body condition is the result of a decrease in the availability of forage fish, especially Atlantic menhaden. If there are environmental factors affecting the impact of disease, then we need to identify the factors and take steps to mitigate their effects. We need the best scientific information available on the disease including a priority list of 
continued research and monitoring requirements. We need to make sure that any human safety issues are addressed and give a clear message to the public.

\section{Comments, Questions, and Answers:}

Question - What would be the limitations on MD DNR to participate in this integrated work? Are there political boundaries?

Response - Work should be done from a Bay-wide perspective. As we develop ecosystem-based management goals and objectives for the striped bass resource, a Bay-wide perspective is necessary. There are a lot of partners involved in many aspects of the Bay from land management to protecting aquatic resources. It is important to have a clear understanding of everyone's role. During this time of limited funding and manpower we want to ensure that our efforts are not redundant. Keeping all of the partners involved in the process is necessary for an integrated approach. We are just developing the practical steps in implementing ecosystem based fisheries management (EBFM) and we need to inform people about the concept and what it means. Many people don't understand what EBFM is all about. An ecosystem-based fishery management plan (EBFMP) will help integrate the partners. It will provide a good "road map" to get everyone on the same page and keep them on track towards accomplishing Bay-wide goals and objectives. It will provide a forum for discussing ecosystem modeling efforts and help identify factors we should consider. Disease issues have not been well integrated into a Bay-wide approach. It seems like disease considerations have been somewhat of a separate endeavor. The occurrence and prevalence of disease should be examined as part of the overall health of the Bay. Many times disease research results have not reached the managers. Since fish health has not always been integrated into past management approaches, adopting an EBFM approach will be an important improvement. We have to keep in mind that research targets will not always answer the questions so we need to add monitoring to these efforts to get the full picture. People care about the fishing industry and the health of fish. We need to reach out to the economic industry or tourism and make a good connection.

Question - What message does DNR want to give the public?

Response - We need to provide the most accurate picture about the health of the fish in the Bay and provide a very straightforward approach to the public. There is a lot of incorrect information that appears in the newspapers. We need to be timely with what we tell the public and tell them what we do and don't know. We need good public relations but mostly we need to stick to the facts. As a group, we need to establish an internal pathway to share information. People want to know if fish are safe to eat and how to handle them. Is the Bay less or more healthy, etc.?

Question - How do we package stories for the media?

Response - We need to be factual and upbeat to get the public's attention.

Question - Should we be proactive in our media approach?

Response - It is always good to do this but the chances are that the information will not get into the newspapers. However, we have to try to keep on top of the issues.

\section{Lewis Gillingham Virginia Marine Resources Commission (VMRC)}

Statement: VMRC is a regulatory agency and has about 200 employees. Field personnel include 3 individuals involved in stock assessment and 70 law enforcement officers. VMRC relies on the Virginia Institute of Marine Science and other institutions to provide research. VMRC does not directly monitor fish disease. Sister agencies play an active role in monitoring water quality, harmful contaminants in finfish, and bacterial levels in shellfish. Virginia Department of Environmental Quality (DEQ) operates a monthly monitoring program that measures contaminants in finfish. Virginia DEQ issues consumption advisories when contaminant levels exceed expectable norms. This department also monitors water quality at beaches and will issue advisories or close beaches as appropriate. The Virginia Department of Shellfish Sanitation monitors oysters, clams, and other shellfish primarily for bacterial contamination using water-quality measures over the shellfish beds as an indicator. This department closes beds to harvest when bacterial levels exceed acceptable levels. 
The most important issue to VMRC is how mycobacteriosis impacts striped bass mortality rates and at what age the fish die.

VMRC needs to know how the mycobacteriosis epizootic may be impacting stock assessment. VMRC is interested in the health issues surrounding this disease in order to address public concerns regarding the health of the striped bass and the percentage of fish that are impacted by this disease.

\section{Comments, Questions, and Answers:}

Question - Maryland has an agency to monitor the health of striped bass but Virginia doesn't. How can we get more information from Virginia waters? Is CHESMMAP a VMRC project?

Response - CHESMMAP started out as a NOAA-funded project. It is now supported through a combination of Federal and State funds. CHESMMAP is a good example of a multiple species monitoring effort. Hopefully, CBPO will have a monitoring program where there will be a clearinghouse for tools, models, and research. There are some funds available in Virginia to support striped bass research. Research funds are available from the Virginia Saltwater Recreational Fishing Development Fund. Money for this fund comes for the sale of saltwater fishing licenses. Each year 1.2 to 1.5 million dollars for projects is available with some funds committed to ongoing projects. 


\title{
Prioritized Research Needs
}

\author{
Facilitators \\ Fred Kern - NOAA/NOS Oxford Cooperative Laboratory and \\ Frank M. Panek - USGS, Leetown Science Center
}

Attendees were split into two groups to discuss prioritization of research needs based on knowledge gaps identified in the State of Knowledge session. Participants in each group were asked to rank the previously identified knowledge gaps based on importance to understanding the overall issues pertaining to mycobacteriosis in striped bass with an emphasis on the information needs presented by the resource managers. The rankings were synthesized in a joint session immediately following the concurrent breakout sessions.

In the prioritization of research needs, it was recognized that beyond specific research projects, there are overarching themes that need to be considered, as well as mechanisms for enhancing the utility of information gathered by various research groups. These overarching themes include standardized approaches and unified databases (research integration) and socioeconomic considerations. See Appendix 2 for graphic presentation of this information and its preferred timetable for implementation.

\section{Standardized Approaches and Unified Databases (Research Integration)}

1. Continued Development of Diagnostic Tools: In discussions of knowledge gaps, the need for rapid tools for identification and quantification of mycobacteria to the species level was perceived as critical for future efforts. Current bacterial culture-based methods are time consuming, prone to contamination, and somewhat limited in application. Biomolecular tools hold much promise for expanding the scope of current efforts, and are currently being pursued by research institutions. Method development was perceived as an ongoing process with technological advancements, and thus an extremely important overarching need for the study of mycobacteriosis and mycobacterial ecology.

2. Standardized Monitoring and Assessment Methodologies: Field monitoring efforts are conducted by several academic institutions and State and Federal agencies within the Bay. Sampling strategies and disease status assessment methodologies vary among these groups, making data collected difficult to compare. It was recognized that both coordinated sampling efforts and standardized methods would allow for more efficient sampling and better data compatibility.

3. Centralized Data Management: Standardization of monitoring and assessment methodologies is the key to the development of centralized data management. Resource managers in particular felt this would allow for the application of new approaches to large data sets which may lead to increased understanding of the dynamics of this disease in striped bass.

\section{Socioeconomic Considerations}

1. Economic Impacts on the Fishery and Related Industries: Striped bass is a commodity supporting significant industries for recreational and commercial fisheries within Chesapeake Bay. It was recognized by the workshop participants that addressing the impact of mycobacteriosis on both the recreational and commercial harvest was important. While there is no direct evidence of acute or chronic mortality on striped bass in the Bay resulting from infection, the presence of external lesions on fish may have effects on both of these fisheries. The effects of public perceptions of this fish disease on commerce must be considered. Socioeconomic data should be integrated into outreach programs aimed at the fishing public.

2. Public Health Outreach: The group recognized that the potential exists for transmission of certain mycobacterial species from fish to humans. Therefore, increased coordination of findings with public health departments and outreach are an overarching concern.

\section{Specific Research Needs}

In the prioritization of research needs, general categories were identified and ranked in order of priority. Specific research questions contributed by the group are ranked in order of priority within the timeframe in which results may be expected. Those categorized as short term reflect the potential for the question to be addressed within 2 years, while longterm questions may require 5 or more years of research efforts 
before answers can be derived. See Appendix 2 for graphic presentation of this information. The specific research needs within each of these prioritized areas are not listed in any particular order.

1. Population Level Impacts/Distribution: Considerable attention was focused on the issue of mortality associated with mycobacteriosis in striped bass, and gaining a better understanding of the distribution of disease. Several questions were raised by the workshop participants concerning the information needs from ongoing research.

An ongoing project is addressing the potential association between mycobacteriosis and natural mortality in striped bass. Additional studies are evaluating the possible increase in natural mortality without reference to specific etiologies. Ongoing studies are also examining spatial, temporal, and age- and sex-specific differences in mycobacteriosis prevalence in the resident Chesapeake stocks and coastal migratory stock. These types of studies need to be expanded to better define the impacts, distribution, and prevalence of mycobacteriosis in striped bass outside Chesapeake Bay and thus determine if the Bay is the epicenter for this disease. Consideration also needs to be given on how this type of data could be included in the development of multi-species population dynamics and ecosystem models.

Questions involving the sub-lethal effects of mycobacteriosis on striped bass immune function, reproduction, and other physiologic capabilities could be addressed in shortterm projects. So, too, could the examination of existing data sets for density-dependent effects associated with particularly strong year classes and seasonal differences in disease prevalence, presentation, and severity. Longterm research questions include determining if striped bass develop immunity to mycobacterial infections and if infections influence striped bass migration patterns within the Chesapeake and along the Atlantic Coast.

2. Mycobacterial Ecology/Routes of Exposure: Highlighted among group discussion was the lack of information on the ecology of environmental mycobacteria. Almost nothing is known about the distribution of mycobacteria outside their piscine hosts. There is also very little known about how the bacteria are transmitted to fish.
Ongoing research includes the development of rapid, sensitive, and specific quantitative tools for environmental mycobacterial community assessment. Additional ongoing research is examining the potential for vertical transmission of mycobacterial infections, the prevalence and distribution of mycobacterial infections within striped bass prey items and parasites, and the relative role of different mycobacterial isolates in causing disease in striped bass.

Questions involving the possible role of environmental factors ( $\mathrm{pH}$, salinity, temperature, etc.) on the growth of the relevant mycobacteria could be completed in the short term. So, too, could investigations of other forms of mycobacterial transmission including water-borne, ingestion, trauma, and vectors. A long-term effort will be required to address issues such as the environmental distribution of the Mycobacterium spp. impacting Chesapeake Bay striped bass, identifying the environmental factors that influence mycobacteria distribution, and the evaluation of possible mycobacteria strain-based virulence differences relative to health risks to striped bass and humans.

3. Impacts of Environmental Stressors: Epizootics of disease are often the result of complex interactions among the host, the pathogen, and the environment. Two leading hypotheses have surfaced concerning the issue of environmental stressors. One questions the influence of water quality (temperature, hypoxia, eutrophication) on host susceptibility and disease progression. The second questions the influence of shifts in striped bass diet and prey availability. Some work has been completed or is ongoing in these areas, but much research remains. Additional short-term research should address the influence of environmental stressors on susceptibility and progression of disease associated with various species/strains of mycobacteria. Identifying genetic factors within the host that make them more susceptible to these pathogens or stressors was also identified as a research need. As little is known in this area, detailed answers would likely require a long-term research commitment. 


\title{
Research Integration and Role of Federal Agencies
}

\author{
Facilitators \\ Kevin Sellner - Chesapeake Research Consortium and \\ Frank Panek - USGS, Leetown Science Center
}

The following issues were addressed by workshop participants.

1. How can monitoring and assessment surveys become a shared resource for mycobacteriosis researchers in the Bay watershed and be made more cost effective in approach?

Two critical factors were identified relative to this question, standardized methodologies and centralized data management. The Chesapeake Bay Consortium recently held a joint workshop with NOAA Chesapeake Bay Office on fish stock assessment in the Bay. This workshop recognized that the difference in the type of data collected, collection methods, and data accessibility between states and agencies makes data integration difficult, if not impossible. State and Federal funding levels are decreasing, so it is more important than ever that some kind of shared resource for these data be developed. The proceedings from this workshop include recommendations for such integration. For instance, coordinated trawling programs for the mainstem Bay and its tributaries could benefit several State and Federal programs. The basic issues described in the stock assessment workshop are nearly identical to those faced by those involved with mycobacteriosis in striped bass. The need and justification for standardized methodologies are identical and seem to be a logical, overriding priority.

2. The participants recognized that research redundancies have existed in the past and that with limited resources; these redundancies diminish our collective abilities to meet science and management objectives. In order to address this problem we need to define what can be done to improve communication. As a first step in this direction, the workshop participants made several recommendations for centralized data management and communications. A clearinghouse for compilation of ongoing research projects is clearly needed. The National Institutes of Health Center of Excellence Program is an example of a web site for collecting resource data in a format that is user-friendly to the scientists and managers. It was suggested that an annual meeting of a steering committee, with a written statement of purpose, a publication, methodology guidelines, and a web site is a direction that the group should consider for the future. Establishing a
Consortium on Aquatic Animal Health issues might be a possibility. This could potentially be a Chesapeake Bay Program workgroup under the Living Resources Subcommittee that reports to the Resource Assessment Work Group on stress indicators. Having a person on the standing committee of the Atlantic States Marine Fisheries Commission to address the aquatic animal health issues in the Bay and mid-Atlantic region might also provide the needed coordination. The Annual Eastern Fish Health Workshop (EFHW) may be another potential venue for an annual meeting (cosponsored by USGS and NOAA Oxford) on mycobacteriosis in Chesapeake Bay striped bass. Many of the workshop participants regularly attend the EFHW.

Other web-based applications were also discussed by the participants. A website addressing outreach already exists and can be found at http://wwww.MyBay.umd.edu. This website is modeled after the Sea Grant data-rich resource for academia and agencies. It might be possible to dedicate a page within this web site to aquatic animal health and link to other resources of interest to Bay researchers and managers. A list-serve for sharing emails among colleagues was also suggested and could also be located on the web site. A participant list with contact information published with the proceedings from this workshop would be a first and very simple step to foster improved communications.

3. Given that mycobacterial infections in striped bass is an emerging issue in the Bay and that priorities are shifting in conjunction with declining budgets, where should we look for new or alternative sources of funding? The list of potential funding sources identified during this session were as follows: National Science Foundation Disease Program (primary focus on modeling); Virginia Saltwater Recreational Fishing Development Fund; National Institute for Environmental Health; Virginia Environmental Endowment (private funding); NOAA Living Marine Resources Program; U.S. Environmental Protection Agency STAR grants; U.S. Department of Agriculture Aquaculture funding through ARS (disease/pathogenesis research); Allied Signals; Coastal America (USGS and NOAA as partners); and NOAA CBSAC - Integrated Research Program. 


\section{Appendixes}

Appendix 1: Workshop Agenda

.35

Appendix 2: Prioritized Research Agenda with Estimated Timelines for Completion .............37

Appendix 3: Participant List

..38 


\section{Appendix 1: Workshop Agenda.}

\section{Day 1: Tuesday, May 9, 2006}

$0630-0745$ Breakfast

0800 - 0815 Opening Remarks and Introductions (Bob Wood - NOAA/NOS Cooperative Oxford Laboratory, Frank Panek - USGS, Leetown Science Center, Chris Ottinger - USGS, Leetown Science Center, John Jacobs - NOAA/NOS Cooperative Oxford Laboratory)

\section{Moderator: Bob Wood (NOAA/NOS Cooperative Oxford Laboratory)}

0815 - 0845 Eric B. May (University of Maryland) - A historical perspective on diseases of striped bass with emphasis on mycobacteriosis.

0845 - 0915 Howard Kator (Virginia Institute of Marine Science) - The ecology of mycobacteria infecting striped bass (Morone saxatilis) in Chesapeake Bay: A research plan.

0915 - 0945 Frank M. Panek (USGS, Leetown Science Center) - Striped bass mycobacteriosis: A zoonotic disease of concern in Chesapeake Bay.

$0945-1000$ Break

\section{Moderator: Christine L. Densmore (USGS, Leetown Science Center)}

1000 - 1030 Laurence Pieper (Maryland Department of Natural Resources) - Striped bass disease overview for the past ten years plus.

1030 - 1100 Mark A. Matsche (Maryland Department of Natural Resources) - Survey of gametes and juvenile striped bass (Morone saxatilis) for mycobacteriosis from the Chesapeake Bay: Sampling methods, external lesions, and histopathology.

1100 - 1130 Cynthia B. Stine (University of Maryland) - Microbiology of gametes and age 0-3 striped bass (Morone saxatilis).

1130 - 1200 Christopher A. Ottinger (USGS, Leetown Science Center)- Mycobacterial infections in striped bass (Morone saxatilis) from upper and lower Chesapeake Bay: 2002 and 2003 pound net studies.

$1200-1245$ Lunch

Moderator: Chris Ottinger (USGS, Leetown Science Center)

1245 - 1315 David T. Gauthier (Virginia Institute of Marine Science) - Epizootiology of mycobacteriosis in Chesapeake Bay striped bass (Morone saxatilis): Large-scale field survey.

1315 - 1345 Andrew S. Kane (University of Maryland) - Mycobacteriosis in juvenile Atlantic menhaden.

1345 - 1415 John M. Jacobs (NOAA/NOS Oxford Cooperative Laboratory) - The influence of dietary intake on the progression and severity of mycobacteriosis in striped bass (Morone saxatilis).

1415 - 1445 Andrew S. Kane (University of Maryland) - Mycobacteriosis in Chesapeake Bay fishes: Perspectives and questions.

$1445-1500$ Break

Moderator: John Jacobs (NOAA/NOS Cooperative Oxford Laboratory)

1500 - 1530 Anothony S. Overton (Eastern Carolina University) - Initial investigation of the overall health and presence of mycobacteriosis in Roanoke River, NC, striped bass (Morone saxatilis).

1530 - 1600 Christine L. Densmore (USGS, Leetown Science Center) - Mycobacterial infections in striped bass (Morone saxatilis) from Delaware Bay.

1600 - 1630 Desmond M. Kahn (Delaware Division of Fish and Wildlife) - Tag-recapture data from Chesapeake Bay striped bass indicate that natural mortality has increased.

1630 - 1700 Wolfgang K. Vogelbein (Virginia Institute of Marine Science) - Epizootic mycobacteriosis in Chesapeake Bay striped bass: What is the fate of infected fish?

$1730-1930$ Review panel discussion of technical summaries and associated presentations. 


\section{Appendix 1: Workshop Agenda.-Continued}

\section{Day 2: Wednesday, May 10, 2006}

$0630-0745$ Breakfast

0800 - 0815 Opening Remarks (Chris Ottinger and John M. Jacobs)

0815 - 1015 Group Discussion: State of knowledge (Facilitators: Chris Ottinger and John M. Jacobs)

$1015-1030$ Break

1030 - 1130 Panel: Perspective of resource managers (Moderator: Frank M. Panek)

1130 - 1300 Lunch (Review panel makes determination on state of knowledge and knowledge gaps - mostly completed on previous evening)

1300 - 1330 Review Panel Presentation: State of knowledge and knowledge gaps (Vicki Blazer - USGS/Leetown Science Center)

1330 - 1530 Break-Out Session: Research prioritization (Facilitators: Frank M. Panek and Fred Kerns - NOAA/NOS Cooperative Oxford Laboratory)

$1530-1545$ Break

1545 - 1645 Summary and group discussion of research prioritization session (Facilitators: Frank M. Panek and Fred Kern)

1715 - ? Development of final recommendations for research prioritization by review panel.

\section{Day 3: Thursday, May 11, 2006}

$0630-0745$ Breakfast

0800 - 0815 Opening Remarks (John M. Jacobs and Chris Ottinger)

0815 - 0900 Review Panel Presentation: Research prioritization (Vicki Blazer)

0900 - 1100 Break-out sessions for research integration, agency roles, awareness and funding (Facilitators: Kevin Sellner - Chesapeake Bay Consortium and Frank M. Panek)

$1100-1115$ Break

1115 - 1200 Summary and group discussion of integration and roles sessions (Kevin Sellner and Frank M. Panek)

$1200-1300$ Lunch

1300 - 1320 Workshop Summary (Chris Ottinger and John M. Jacobs)

1320 - 1400 Observer/press questions, closing remarks, and adjournment (Facilitator: Chris Ottinger) 


\section{Appendix 2: Prioritized Research Agenda with Estimated Timelines for Completion.}

\begin{tabular}{|c|c|c|c|}
\hline & Ongoing & 2 year & 5 year \\
\hline \multicolumn{4}{|c|}{ Overarching Themes } \\
\hline \multicolumn{4}{|l|}{ 1. Standardized Approaches and Unified Databases } \\
\hline \multicolumn{4}{|l|}{ B. Standardized monitoring } \\
\hline \multicolumn{4}{|l|}{ C. Improved coordination among investigators } \\
\hline E. Establish steering committee for B, C, and D & & & \\
\hline
\end{tabular}

\section{Socioeconomic Considerations}
A. Outreach programs and web-based information
B. Interaction with public health agencies
C. Development of tools to assess economic impacts of disease
D. Monitoring of economic impacts of disease
E. Human-health/food-safety issues

\section{Specific Research Priorities}

\section{Population Level Impacts and Distribution}
A. Estimates of mortality associated with disease
B. Spatial and temporal distribution within Bay and Coast-wide fishery
C. Sub-lethal effects on immune function, reproduction, growth, and fitness
D. Density-dependent effects
E. Seasonal effects
F. Movement of diseased fish within the coastal fishery
G. Integration of disease into stock assessment models

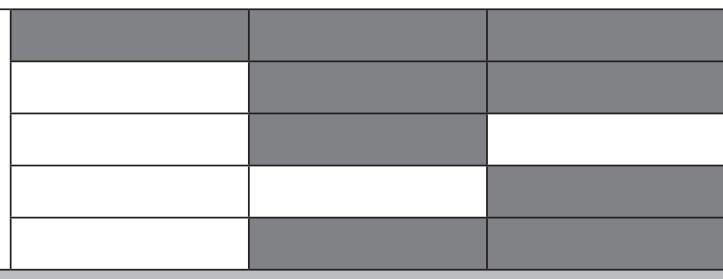

2. Mycobacterial ecology/routes of exposure
A. Transmission studies
B. Distribution in potential vectors (prey/parasites)
C. Relative roles of pathogens in causing disease
D. Growth requirements of various isolates
E. Identification of potential sources
F. Life cycle (obligate vs. opportunistic?)
G. Strain variability and virulence factors
H. Genetic determinants of susceptibility
I. Potential for development of immunity

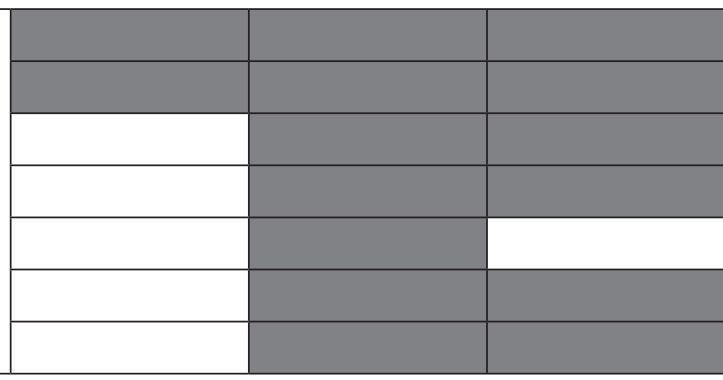

\section{Impacts of Environmental Stressors}
A. Influence of environmental variables on disease progression
B. Nutritional/dietary factors influencing progression
C. Genetic/immune factors and stressors
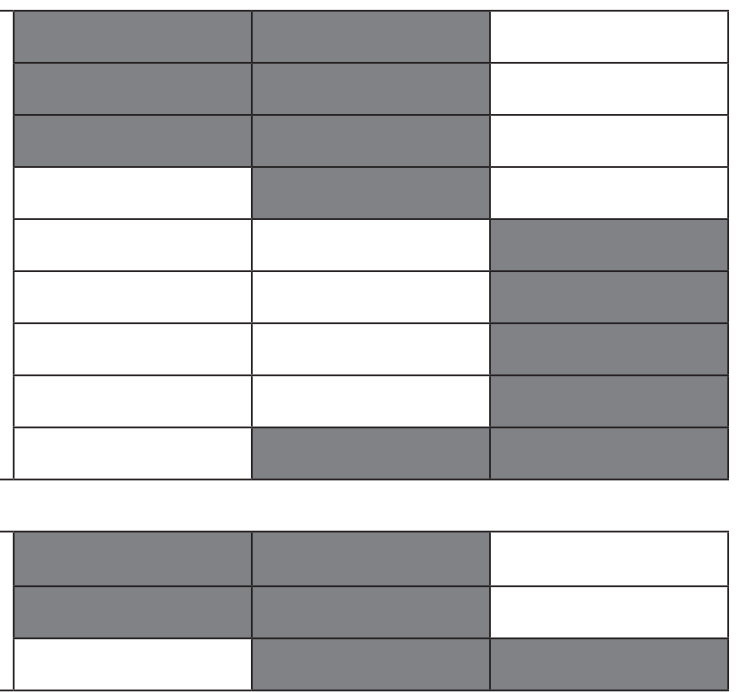


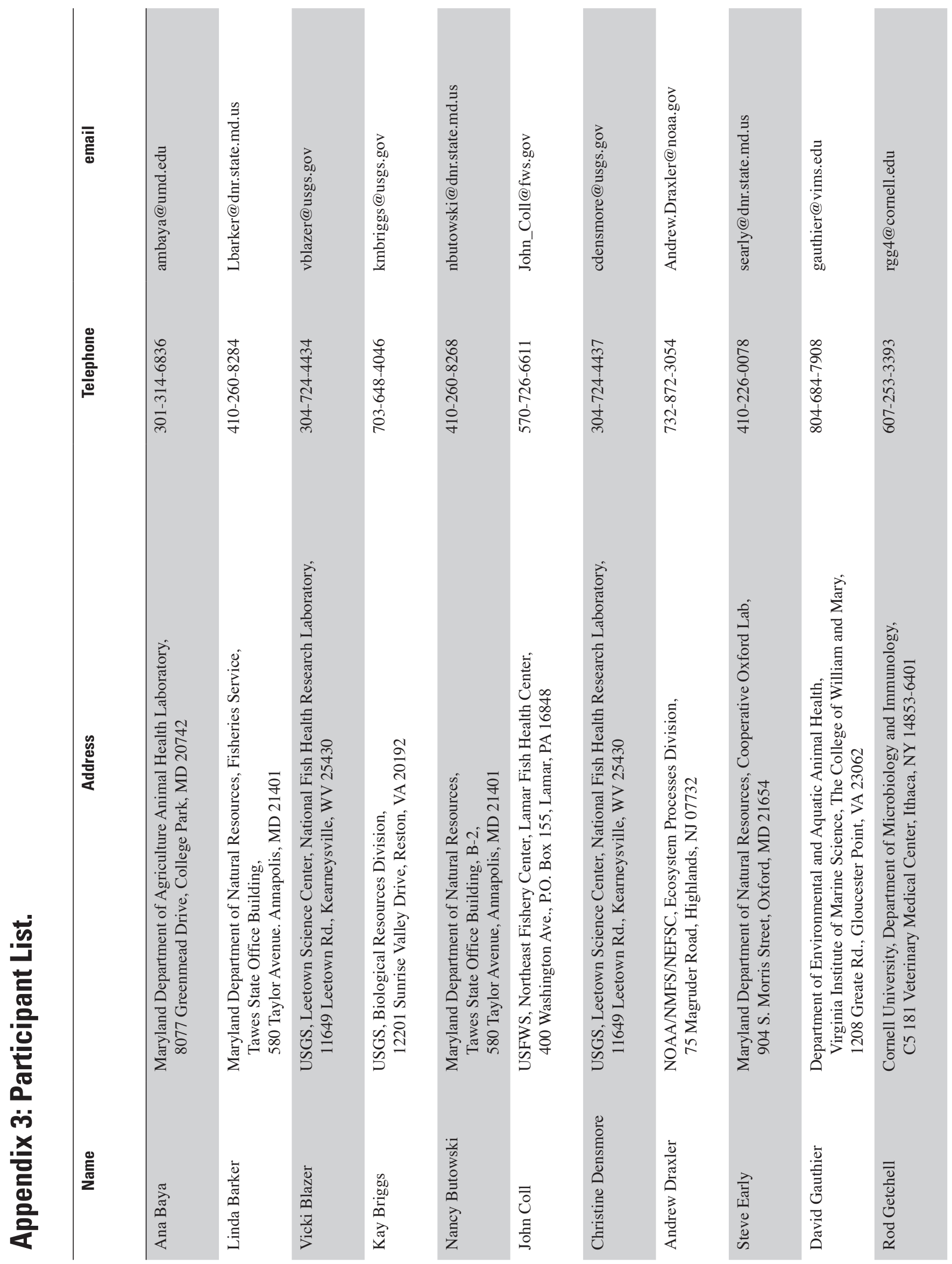




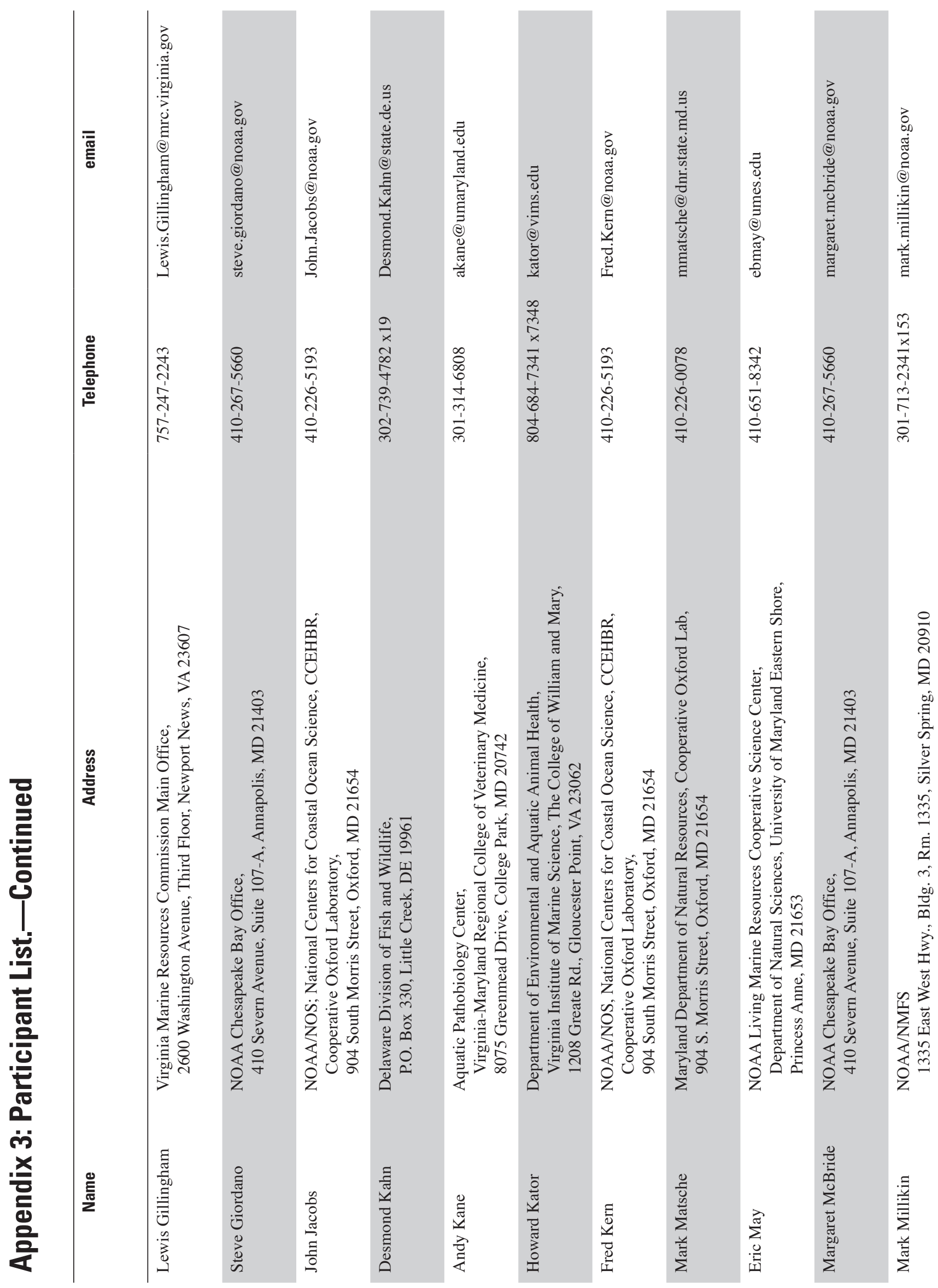




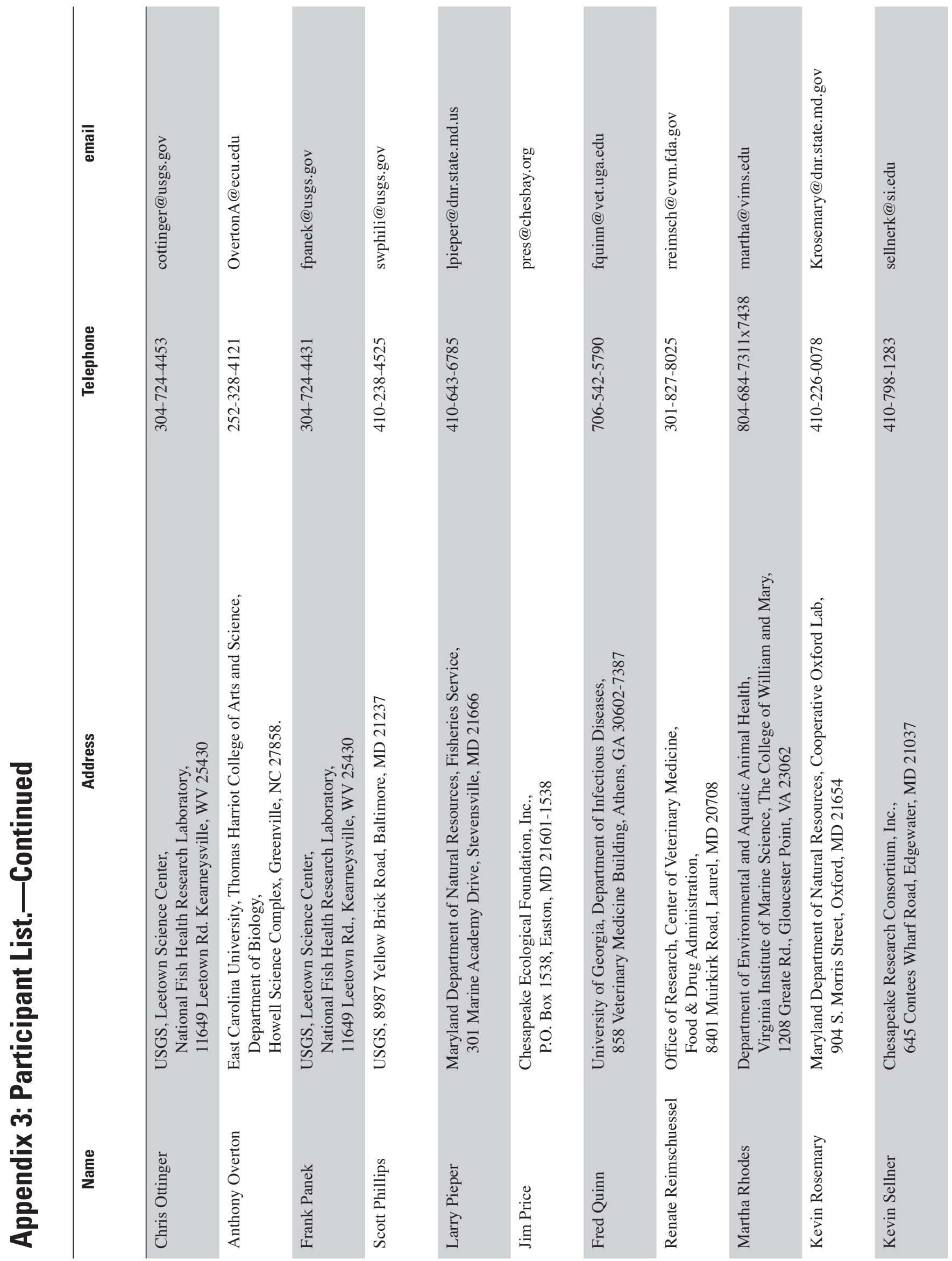




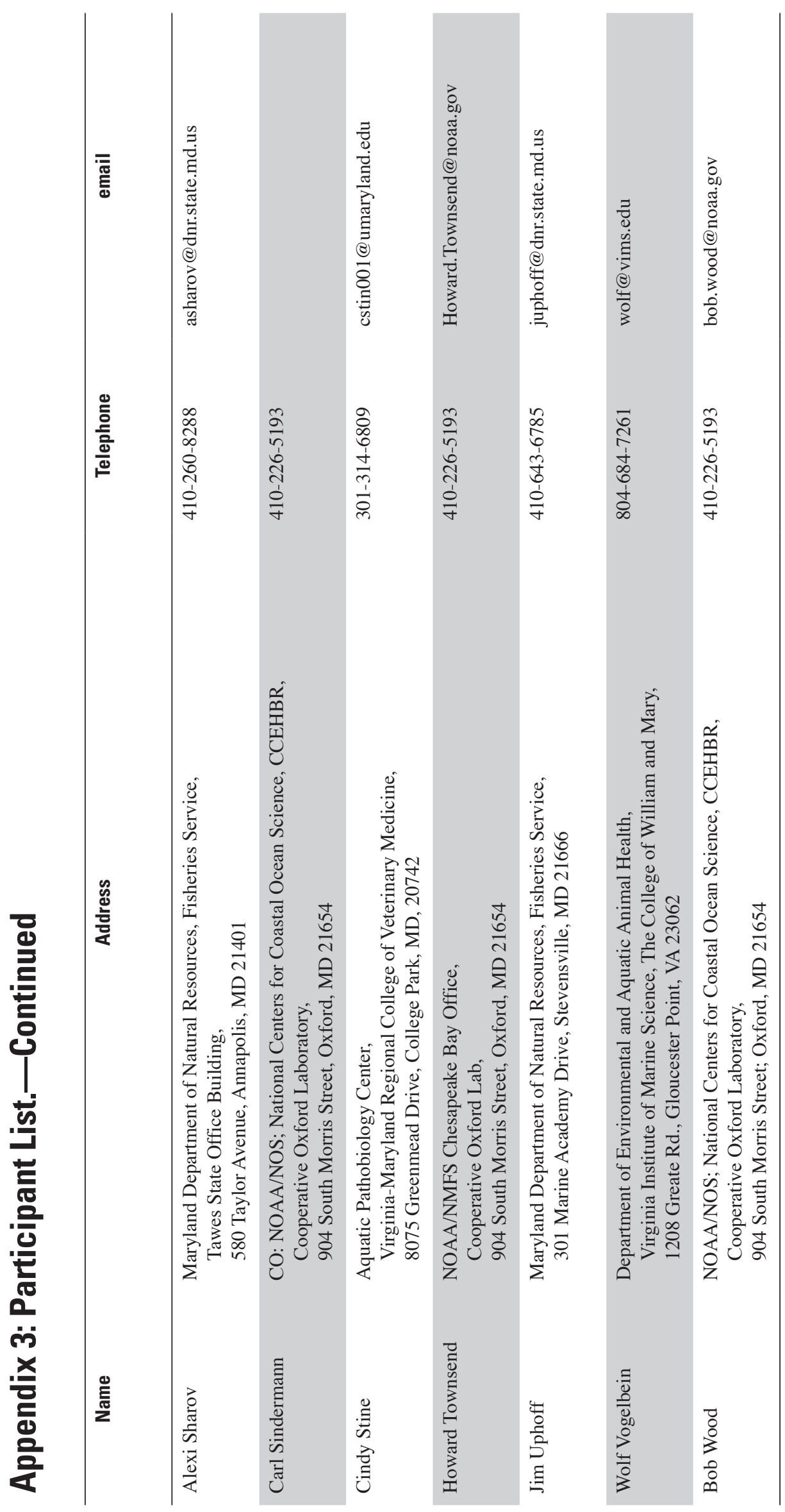


For additional information:

Christopher A. Ottinger

U.S. Geological Survey

Leetown Science Center

11649 Leetown Road

Kearneysville, WV 25430

John M. Jacobs

National Oceanic and Atmospheric Administration

National Centers for Coastal Ocean Science

Cooperative Oxford Laboratory

904 South Morris Street

Oxford, MD 21654 


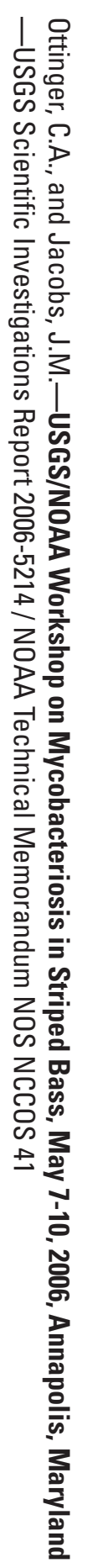

(8) Printed on recycled paper 